\title{
CALCULATING HURST EXPONENT WITH THE USE OF THE SIROKY METHOD IN DEVELOPED AND EMERGING MARKETS
}

\author{
Krzysztof Borowski \\ Warsaw School of Economics
}

ORCID: https://orcid.org/0000-0003-0434-7573

Michał Matusewicz

Warsaw School of Economics

ORCID: https://orcid.org/0000-0001-6998-5838

\begin{abstract}
Abtract
The purpose of the article This paper analysis Hurst exponents calculated with the use of the Siroky method in two time intervals of $625\left(H_{625}\right)$ and $1250\left(H_{1260}\right)$ sessions for the following assets: (the number of assets for a given group in brackets): Stock indices (74), currency pairs divided into segments: USD exchange rate in relation to 42 other currencies (USDXXX), EURO exchange rate in relation to 41 other currencies (EURXXX), JPY exchange rate in relation to 40 other currencies (JPYXXX) and other currency pairs (12). In total, 209 financial instruments were analyzed.
\end{abstract}

Methodology: Hurst coefficient calculation with the use of the following methods; Siroky, Detrended Moving Average (DMA) and Detrended Fluctuation Analysis (DFA).

Results of the research: The Hurst coefficient values calculated with the use of Siroky method are similar to the results obtained using DFA and DMA methods. The second main conclusion that was drawn from the research may be formulated as follows: exchange rates calculated for the developed-developed country currencies are more effective than in the case of the developed-emerging countries group.

Keywords: Hurst exponent, market efficiency, developed countries.

JEL Class: G10, G14. 


\section{INTRODUCTION}

There is a wide spectrum of mathematical tools constructed to analyze processes characterized by long-term data dependence. One of the important turning points in long-term data series analysis is a method of scaled range analysis, proposed by Hurst [Hurst 1951: 770-799]. The starting point in Hurst's work was Einstein's study of Brownian motions, in which the relationship of the distance $r$ covered by the molecule during time $t$ was expressed in the following form [Einstein 1908: 469-502]:

$$
r=c \cdot \sqrt{t}
$$

where:

$c$ - represents a constant.

This equation mainly concerns the case when the sequence of increments of the molecule's path in time is random walk, characterized by the independent random variables normally distributed [Weron and Weron 1998; Kapecka 2015: 5-75]. Meanwhile, the results obtained by Hurst led to the conclusion that the overwhelming number of natural phenomena (like: temperature changes, river and sea floods, atmospheric precipitation, sunspot activity) are not subject to random walk, but constitute the so-called processes with long-term memory, called later on as fractional Brownian motion, representing the superposition of trend and noise [Peters 1997: 64; Mastalerz-Kodzis 2003: 37-38].

For the scaled range method, the Hurst exponent is defined by the following formula [Peters 1997: 64]:

$$
\left(\frac{R}{s}\right)_{n}=a \cdot n^{H}
$$

where:

$R$ - range of fluctuations,

$S$ - standard deviation,

$\left(\frac{R}{S}\right)_{n}$ - so-called scaled range,

$a>0$ - positive constant,

$n \in N$-number of time series observations. 
Calculating the logarithm of both sides of the equation (1) leads to the following formula for $\ln \left(\frac{R}{S}\right)_{n}$ :

$$
\ln \left(\frac{R}{S}\right)_{n}=H \cdot \ln (n)+\ln (a)
$$

To compute the Hurst exponent, first it necessary to estimate the scaled range $\left(\frac{R}{S}\right)_{n}$ for different $n$, and then solve equation (2) using linear regression. The Hurst exponent is a regression coefficient, estimated with the use of the least squares method. This method was further improved by Mandelbrot and Wallis [Mandelbrot and Wallis 1968].

Depending on the needs, methods determining the Hurst exponent can be used to study one-dimensional time series:

a) Long range analysis method (R/S) [Hurst 1951: 770-799],

b) Detrended Moving Average (DMA) [Alessio et al. 2002: 197-200; Mantenga and Stanley 1995: 46-49],

c) Detrended Fluctuation Analysis (DFA) [Bunde and Havlin 1995: 97-100; Peng et al. 1994],

d) Generalized Hurst Exponent (GHE) [Di Matteo et al. 2003: 183-188], or multidimensional:

a) Multifractal Detrended Fluctuation Analysis (MF-DFA) [Abry and Weitch 1998; Kantelhard et al. 2002],

b) Wavelet Transform Module Maxima (WTMM) [Muzy et al. 1994: 245 $-302]$.

Another method for determining the Hurst exponent is the box method, which covers the graph of the analyzed function with a square grid with a certain side and counting the squares having at least one point in common with the examined graph. Then the grid is considered with a side that is $k$ times smaller and the squares having at least one point in common with the analyzed graph are counted again [Voss 1991: 816-817; Mastalerz-Kodzis 2003]. This method was applied, among others by Ehlers to create the Fractal Adaptive Moving Average [Ehlers 2005: 81-82]. In turn, Ehlers and Way modified the box method to include not only closing prices, but also the highest and lowest prices in the analyzed period [Ehlers and Way 2010: 16-20].

There is a close relationship between the Hurst exponent and Minkowski's fractal dimension $(d)$ [Kowgier 2009: 157-167]:

$$
d=2-H
$$


Such relationship with the use of the fractional Brownian motion and self-similarity of the stochastic process was presented in the work of Kowgier [Kowgier 2009: 157-167]. Estimation of the fractal dimension is justified because it enables to gain additional knowledge about the behavior of prices and rates of return, and thus contributes to a better understanding of their nature. A concept of fractal dimension as a measure of risk on the equity market is described in the paper of Orzeszko [Orzeszko 2010: 57-70]. The author presents the application of this method for selected indexes of the Warsaw Stock Exchange. In the further part of this paper, the fractal dimension $(d)$ will be treated as a risk measure.

The method of calculating the Hurst exponent proposed by Siroky [Siroky 2017: 18-21 and 45] directly refers to the method of calculating the fractal dimension using the slope coefficient of sub-segments of the analyzed time window, whose authors are Ehlers and Way [Ehlers and Way 2010: 16-20]. According to the method of segment division, the analyzed time series should be divided into two segments of equal data length, with $S_{2}$ as the slope factor in the current data segment and by $S_{1}$ in the previous one. The slopes $S_{2}$ and $S_{1}$ are defined as follows (,, " in the denominator means a single calculation period for analyzed segment) [Siroky 2017: 20]:

$$
\begin{gathered}
S_{2}=\frac{H_{2}-L_{2}}{1}=H_{2}-L_{2} \\
S_{1}=\frac{H_{1}-L_{1}}{1}=H_{1}-L_{1}
\end{gathered}
$$

where:

$H_{1}$ and $H_{2}$ - the highest price in the first and second data segments, respectively, $L_{1}$ and $L_{2}-$ the lowest price in the first and second data segments, respectively.

For the entire analyzed range, the slope factor will be equal to (,2" in the denominator means both calculation periods forming the entire time horizon) [Siroky 2017: 20]:

$$
S_{t o t}=\frac{H_{t o t}-L_{t o t}}{2}
$$


where:

$H_{t o t}$ and $L_{t o t}-$ the highest and lowest prices in the entire data segment, respectively. In turn, the fractal dimension calculated for all data included in the analyzed range will be equal to [Siroky 2017: 20] ${ }^{1}$ :

$$
d=\frac{\ln \left(S_{1}+S_{2}\right)}{\ln (2)}-\frac{\ln \left(S_{t o t}\right)}{\ln (2)}
$$

By dividing the observed range of data into smaller and smaller periods, reaching data for a single session, the slope coefficient becomes equal to the $T R$ (True Range) value proposed by Wilder and equal to the difference between the highest and lowest price in a given session [Wilder 1978]. With this approach, the value of the slope factor for all observed sessions is equal to the value of $R$, divided by the number of sessions $(n)$, where $R$ is equal to the difference between the highest and lowest price in the analyzed time window.

Taking into consideration $n$ session window, the equation 4 may be generalized and the expression for the fractal dimension $d$ will take the following form [Siroky 2017: 20]:

$$
d=\frac{\ln \sum T R-\ln \frac{R}{n}}{\ln n}=\frac{\ln \left(\frac{\sum T R}{\frac{R}{n}}\right)}{\ln n}
$$

Noting that $\sum T R$ is equal to the product of the Mean True Range value $(M T R)$ and the number of observations $(n)$, the expression for the fractal dimension takes the form [Siroky 2017: 45]:

$$
d=\frac{\ln \left(\frac{M T R \cdot n}{\frac{R}{n}}\right)}{\ln n}=\frac{\ln \left(\frac{M T R \cdot n^{2}}{R}\right)}{\ln n}=\frac{2 \cdot \ln n-\ln \left(\frac{R}{M T R}\right)}{\ln n}=2-\frac{\ln \left(\frac{R}{M T R}\right)}{\ln n}
$$

${ }^{1}$ In Siroky's work division by $\ln (2)$ concerns only the second addend of the sum, e.g. $\ln \left(S_{t o t}\right)$, however, in the work of Ehlers and Way, the author quotes, the expression for $d$ takes the form as in formula (4) [Ehlers and Way 2010: 16-20]. 
Based on the relationship (3), the value of the Hurst exponent is determined by the equation [Siroky 2017: 45]:

$$
H=\frac{\ln \left(\frac{R}{M T R}\right)}{\ln n}
$$

The MTR value can also be obtained as the Average True Range indicator, averaged over a given time window, with the latter being calculated on the basis of daily data. Siroky proposes following way of applying the ATR indicator [Siroky 2017: 18-21 and 45]:

$$
\begin{gathered}
M T R \approx \frac{1}{n} \cdot \sum_{t=1}^{t=n} A T R_{t} \\
A T R_{t}=\operatorname{Max}\left(H_{t}-L_{t},\left|H_{t}-C_{t-1}\right|,\left|L_{t}-C_{t-1}\right|\right)
\end{gathered}
$$

where:

$H_{t}$ - highest price on the session $t$,

$L_{t}-$ lowest price on the session $t$,

$C_{t-1}-$ closing price on the session $t-1$.

The clear advantage of Siroky's method is applying not only closing prices, but also the highest and lowest prices in the calculation process, which should be considered as a method more adequate for use on financial markets than others. Unlike the scaled range method, the Siroky method does not impose the condition that the number of session $n$ has many divisors. Therefore, this method should be considered more appropriate for use on financial markets than others. The Siroky method can therefore be used for shorter time intervals, while other methods often require longer time horizons. One drawback of the Siroky method is the use of the approximate $M T R$ value. This approximation becomes negligible for large $n$.

Regardless of the type of time series studied, the Hurst exponent assumes values in the range $(0 ; 1)$, while obtaining boundary values is extremely difficult, therefore they are often considered theoretical. The value of the Hurst coefficient can be interpreted as [Barunik and Kristoufek 2010: 3844-3855]:

a) $H \epsilon(0 ; 0.5)$ - the time series is defined as anti-persistent, characterized by high variability and high probability of frequent changes in the direction of short-term trends. 
b) $H=0.5$ - the time series does not have a dominant trend, which means that subsequent changes take on a random nature (random walk). The probability of both changing the trend and maintaining the current trend is the same and equal to 0.5 .

c) $H \epsilon(0.5 ; 1)$ - the time series is defined as persistent, characterized by low variability and low probability of frequent changes in the direction of short-term trends. In other words, it is a time series with an ordered course, which maintains the current trend (momentum). The higher the Hurst exponent, the higher the course orderliness.

The purpose of this study is to calculate the Hurst exponent with the use of the Siroky method for specific groups of assets: Stock Indices and Currency Market (pairs: USDXXX2, EURXXX, JPYXXX, Other Currency Pairs). In the second part of the paper two rankings of Hurst exponents were created: the first taking into account the average value of the Hurst exponent and the second based on the distance of the Hurst exponent from the level of 0.5.

The authors of this study are not aware of any scientific papers on the calculation of Hurst exponents based on the method proposed by Siroky. Therefore this paper fills in the existent research gap.

Two main theses presented in the paper were formulated as follows:

T1: The Hurst coefficient can be calculated with the use of the Siroky method for the following market segments: equity and currency.

T2: The extension of the investment horizon $(n)$ leads to a reduction in the differences between the Hurst coefficient values:

$$
\begin{aligned}
& H_{\text {Siroky }}-H_{D M A} \\
& H_{\text {Siroky }}-H_{D F A}
\end{aligned}
$$

where:

$H_{\text {Siroky }}-$ Hurst coefficient calculated with the use of the Siroky method,

$H_{D M A}$ - Hurst coefficient calculated with the use of the Detrended Moving Average,

$H_{D F A}$ - Hurst coefficient calculated with the use of the Detrended Fluctuation Analysis.

${ }^{2}$ Contractual notation denoting the exchange rate of pairs in which USD is one of the currencies. An analogous convention was used for EURXXX and JPYXXX. 


\section{LITERATURE REVIEW}

The long-memory of S\&P 500 index have been investigated in numerous empirical studies that have provided confuring results. For example Peters testing the persistence in the US stock market proved the evidence of long memory [Peters 1991; Peters 1994]. Granger and Ding on the basis of 17000 daily observations of the S\&P 500 index concluded that absolute returns exhibited long-memory properties, a later study of Granger and Hyung confirmed these findings [Granger and Ding 1995: 67-91; Granger and Hyungh 2004: 399-421]. Alvarez-Ramirez et al. used daily data for the period 1950-2007 and reported that the long-run memory properties of the S\&P 500 index changed over time, especially during crisis periods [Alvarez-Ramirez et al. 2008: 6159-6169]. Similar conclusions were published by Dominique and Rivera, who proved the S\&P 500 index to be persistent, but its degree of persistence changes over time [Dominique and Rivera 2011: 1-6]. On the contrary, Chow et al. did not find long-term dependence in stock returns [Chow et al. 1996: 181-194]. The same conclusion was reached by Caporale and Gil-Alana, as well as by Lu and Perron, who did not find evidence of long memory in daily S\&P 500 index returns [Caporale et al. 2016: 235-257; Lu and Perron 2010: 138-156].

Financial data time-series and their persistence were analyzed very thorough in case of different types of financial markets:

a) Stock markets [Greene and Fielitz 1977: 339-349; Lo 2004: 15-29; Cheung and Lai 1995: 597-615; Jacobsen 1995: 37-52; Opong et al. 1999: 267 -282; McKenzie 2001: 393-406; Costa and Vasconcelos 2003: 231-248; Los and Yalamova 2006: 106-133; Onali and Goddard 2010],

b) Commodities markets [Cheung and Lai 1995: 597-615; Barkoulas et al. 1997: 737-745; Crato and Ray 1999; Alvarez-Ramirez et al. 2002: 651-670; Serlatis and Roenberg 2009: 2007-2015],

c) FOREX [Mulligan 2000: 33-49; Kim and Yoon 2004: 272-278; Da Silva et al. 2007: 1-11].

There is popularity of country stock market index research. In many papers the long-term memory of the analyzed market was proved [Greene and Fielitz 1977: 339-349; Peters 1991; Peters 1994; Hja and Lin 2007: 537-540; Lento 2009; Onali and Goddard 2010]. In others the conclusion about random nature of prices fluctuations and absence of the long-term memory of the markets, was presented [Lo 1991: 1279-1313; Jacobsen 1995: 37-52; Berg and Lyhagen 1996; Crato and Ray 1999; Batten et al. 2003; Serletis and Rosenberg 2009: 325-332]. Onali and Goddard analyzing returns for Italian Mibtel and Czech PX indexes found the evidence of long-range dependence in the logarithmic return series [Onali and Goddard 2010]. Batten et al. using the modified rescaled range test for daily Nikkei returns in the period of 1980-2000, accepted the null hypothesis of 
lack of long-term dependence for the whole sample and every sub-period [Batten et al. 2003]. The same hypothesis was rejected for classical rescaled adjusted range test. Berg and Lyhagen computing monthly returns in the period of 1919 -1995 , as well as returns for weekly data of the period 1980-1995, hardly found any evidence of long run dependence [Berg and Lyhagen 1996]. On the basis of three different tests that were robust to short term dependence proved that the modified R/S test and ARFIMA-GARCH tests provided no support for long-run memory in Swedish stock returns. Lo analyzing daily returns for US stock market in the period of 1872-1986 could not find long-term dependence [Lo 1991: 1279 -1313]. Jacobsen taking into consideration indexes of five European countries, USA and Japan rejected the hypothesis of long term dependence in the analyzed data series [Jacobsen 1995: 37-52].

Corazza and Malliaris calculating Hurst exponent on the basis of R/S method for forex market in the period of 1972-1994 proved that Hurst exponent was statistically different from 0.5 and changed dynamically over time [Corazza and Malliaris 2002: 387-401]. Glenn assessing $H$ exponent with the use of R/S method for daily returns of NASDAQ index, obtained the value of $H$ equal to 0.59 and proved that the $H$ exponent increased monotonically to a value of 0.87 for 250-session returns [Glenn 2007].

Barkoulas and Baum analyzing data for three stock indices: DJIA, NASDAQ and S\&P 500 and seven sectoral monthly stock indices, and daily prices for the 30 companies included in the Dow Jones Industrials Index, did not find evidence of long-range behavior for US equities [Barkoulas and Baum 1996: 253-259] .

Hiemstra and Jones applied the modified rescaled range test to the return series of 1952 common stocks in US and came to the conclusion that there was some evidence consistent with persistent long memory in the returns of a small proportion of stocks [Hiemstra and Jones 1997: 373-401]. On the other hand, Huang and Yang on the basis of companies included in the indexes: NYSE and NASDAQ were using intraday returns proved the existence of long memory [Huang and Yang 1999]. Cheung and Lai analyzed 18 countries founding small support for long memory in the international stock returns [Cheung and Lai 1995: 597-615]. Henry investigated long run dependence for nine international stock indexes and provided evidence of long memory for the German, Japanese, South Korean and Taiwanese stock indexes [Henry 2002: 725-729]. Cajueiro and Tabak studying daily closing prices for equity indexes of 11 emerging markets and two of developed (S\&P 500 and Nikkei 225) in the period of January 1992 to December 2002, ranked countries using a „rolling sample” approach [Cajueiro and Tabak 2004a: 349-352; Cajueiro and Tabak 2005: 671-675]. Long-run dependence measures were more significant for Asian than for Latin American countries (with the exception of Chile), while US and Japan ranked as the most efficient ones. Calculating the Hurst exponent over time and using four years 
window of data for Latin America and Asia stock exchange indexes, Cajueiro and Tabak found the emerging markets have been becoming more efficient over time with the exception of Brazil, the Philippines and Thailand [Cajueiro and Tabak 2004b: 521-537]. Kyaw et al. calculating Hurst exponents for six Latin markets (Argentina, Brazil, Chile, Colombia, Mexico and Venezuela) with the uses of the MF-DFA method, proved that Latin American equity markets are persistent, except for the Colombian and Mexican stock exchanges, which remain anti-persistent [Kyaw et al. 2004].

Di Matteo et al. performed calculations of the Hurst exponent on the basis of the GHE method for the following market indices (the period covered by the analysis is given in brackets): NASDAQ 100 (1900-2001), NIKKEI 225 (1990 -2001), WIG (1990-2001) and JSX (1991-2001), as well as 37 stock indexes (1997-2001) [Di Matteo et al. 2003: 183-188]. They proved that in the case of developed markets, the Hurst exponent values were lower than 0.5 while for less developed markets were higher than 0.5 . In addition, by dividing the analyzed period into groups of 3,000 sessions, the authors indicated that the Hurst exponent values tended to fluctuate below 0.5 ; meanwhile, in the case of JSX and WIG indexes such fluctuations occurred mainly above 0.5 .

Lipka and Los analyzing the daily data of eight stock indexes: ATX (Austria), KFX (Denmark), CAC 40 (France), DAX (Germany), OSLO TOTAL INDEX (Norway), IBEX 35 (Spain), MADRID GEN Index (SMSI - Spain) and FTSE 100 (United Kingdom) for various time intervals (with the largest number of observations, i.e. 4437 collected for the British index, data for the period: April 2, 1984 to October 23, 2000), proved that the values of Hurst exponent, calculated using the modified MF-DFA method, they were lower than 0.5 for all indices, except for the Danish stock exchange index, for which the Hurst exponents was equal to 0.55. For stock indices of Spain, Germany and France, the values of Hurst exponent were slightly lower than 0.5: IBEX (0.46), SMSI (0.48), DAX (0.47) and CAC40 (0.46) [Lipka and Los 2003]. On the other hand, the calculation of Hurst exponent on the basis of the standard MF-DFA procedure ${ }^{3}$ clearly confirmed that the values of all Hurst exponent were lower than 0.5 ; wherein for some equity indexes, these values were only slightly lower than 0.5: Austria (0.48), Norway (0.49), Spain IBEX 35 and SMSI (0.46 each).

Jud proved that in the period 1981-July 2017 the value of the Hurst exponent, calculated for the six-month time intervals of the S\&P 500 index, fluctuated around the value of 0.5 [Jud 2017: 71-75]. Thus, the author demonstrated the existence of two types of periods on the American market: the first in which short-term upward trends dominate and the second type of periods in which there are

${ }^{3}$ IDL Wavelet Toolkit calculation package, developed by Research Systems and available on the website: [www1] http://ion.researchsystems.com/IONScript/wavelet/website 
no such trends. In addition, the sharp decline in the Hurst exponent in 2015, the highest in twenty years, was recognized as one of the reasons for investors' rapid withdrawal of funds from hedge funds. It resulted that mathematical models for investing in line with the trend began to fail. Of course, customers withdrawing funds had no idea about the historical and current values of the Hurst exponent, and they only pointed to the decrease in returns generated by hedge funds. In addition, the author concluded that the values of the Hurst exponent vary depending on the sector to which the given security or stock index is included. In addition, the occurrence of cycles on the graph smoothed using a half-year double exponential moving average (DEMA) of the Hurst exponent has been proven.

Caporale et al. investigating the degree of persistence of market fear in the VIX index over the sample period 2004-2016, as well as some sub-periods, found that its properties changed over time: in normal periods it exhibited anti-persistence, whilst during crisis period the level of persistence was increasing [Caporale et al. 2018: 140-147]. Mynhardt et al. analyzing the persistence of financial markets in the period of 1990-2007 came to similar as above conclusions [Mynhardt et al. 2014]. The values of Hurst exponents for developed countries are equal to around 0.5, what indicated the adequacy of Efficient Market Hypothesis, while values of Hurst exponents calculated for emerging markets tended to 1, indicating the adequacy of Fractal Market Hypothesis. Similar conclusion were made when studying the foreign markets of analyzed countries. Using the Hurst exponent as a criterion of market efficiency, authors proved that the level of market efficiency is different for pre-crisis and crisis periods.

Jagric et al. based on wavelet analysis, estimating the Hurst exponent with the use of sliding time window, tested the existence of long-range dependence in six emerging markets [Jagric et al. 2005: 79-103]. Authors divided analyzed countries into two groups: with strong long-range dependence (Czech Republic, Hungary, Russia and Slovenia) and markets with a weak form of long-range dependence (Poland, Slovakia), while finding also evidence for the time dependence of the Hurst exponent.

Ferreira investigated the behavior of 18 Easter European stock indexes with the use of a sliding window DFA and found the most of the considered indexes to be long-range dependent, but the level of the dependence tented to decrease in time run [Ferreira 2018: 454-470]. The analyzed market were ranked with the help of an efficiency index based on the method proposed by Kristoufek and Vosvrda [Kristoufek and Vosvrda 2013: 184-193]. The following markets: Czech Republic, Hungary and Poland resulted to be the most effective. Domino calculating the Hurst exponent for 126 companies listed on the Warsaw Stock Exchange in the period of 1991-2008, concluded that a decreasing value of the Hurst exponent could be regarded as a signal for a potential change in the present trend [Domino 2011: 98-109]. Caraiani testing the presence of multifractality in 
the main CEE stock markets (Czech Republic, Poland and Hungary) with the use of MF-DFA method, indicated the long-run dependence on these markets, as well as its stability in time run [Caraiani 2012]. The Hurst exponents calculated for following equity indexes: PX, BUX and WIG were equal to $0.57,0.55$ and 0.54 respectively. Czarnecka and Wilamowska examined the WIG20 index for two time intervals (02.01.2014-17.10.2014 and 02.01.2015-16.10.2015) characterized by Hurst exponent belonging to two different ranges. In each of the analyzed time series, for all analyzed instruments, 200 subsequent changes in the price direction were noted (increase, decrease, increase, decrease, etc.) [Czarnecka and Wilimowska 2018]. In selected time intervals, slight downward trends were observed, with the first of them being the anti-persistent series $(\mathrm{H}=0.41)$, and the second one - persistent $(\mathrm{H}=0.6)$.

Raimundo and Okamoto based on the Hurst exponent and scaled range (R/S) for such currency pairs as: AUDJPY, CHFJPY, EUROJPY, GBPJPY and EUROCHF for one-session, one-hour and fifteen-minute time horizons from the period 01.01.2003-30.12.2014, proved the possibility of use of Hurst exponents as a tool for determining the degree of correlation and persistence on currency markets [Raimundo and Okamoto 2018: 116-124]. Their research confirmed earlier results obtained by Corazza and Malliaris, who revealed that the values of Hurst exponents statistically differ from 0.5 for most of the analyzed currency pairs and change dynamically over time, concluding that changes in exchange rates of currency pairs are subject to Brownian motion [Corazza and Malliaris 2002: 387-401].

Kale and Butar certified that the distribution of 500 Hurst exponents, obtained on the basis of R/S method for the analyzed time series, resulted to be normal [Kale and Butar 2011: 8-19]. In the process of analysis the following tests were implemented: Shapiro-Wilk, Kolmogorov-Smirnov and Anderson-Darling. In all cases, the received values of the p-value parameter were significantly greater than 0.05 .

\section{METHODOLOGY}

The research was conducted in the following groups of assets (the number of assets from a given group after the dash):

a) Stock indexes -74 ,

b) Currency pairs divided into segments:

1. USD exchange rate in relation to 42 other currencies (USDXXX),

2. EURO exchange rate in relation to 41 other currencies (EURXXX),

3. JPY exchange rate in relation to 40 other currencies (JPYXXX),

4. Other currency pairs - total 12 . 
In total, prices of 209 financial instrument were analyzed - see Appendix 1.

The selection criterion was the availability of daily data in the following data basis: stooq.pl, investing.pl and bossa.pl.

For each of the assets, the calculations were divided into the following stages:

1. Examination of the normality of the distribution of logarithmic rates of return over the periods:

a) Date of first listing of the instrument $-31.12 .2019^{4}$ (full time window)

b) 625 sessions preceding the session on 31.12.2019 (625-sessions window)

c) 1250 sessions preceding the session on 31.12 .2019 (1250-session window)

In the study of Jud, a 125-session interval was used, corresponding to the six-month horizon. Thus, in the case of the two and a half years and in case of five years investment horizon, the following numbers of sessions should be applied: 625 and 1250, respectively [Jud 2017: 74].

Two hypotheses were formulated:

$\mathbf{H}_{\mathbf{0}}$ : The distribution of return rates in the analyzed time window is a normal distribution.

$\mathbf{H}_{1}$ : The distribution of return rates in the analyzed time window is not a normal distribution.

Three tests were selected for verification of these statistical hypotheses: Jarque-Barre (JB), Shapiro-Wilk (SW) and d'Agostino-Pearson (DA).

The choice of logarithmic rates of return was supported by their basic advantage, i.e. additivity.

This part of the study is auxiliary and aims to make the reader aware of the normality (or not) of the distribution of analyzed rates of return. More information on the relationship between the returns distribution on financial markets and the Hurst ratios can be found, among others in the paper of Barunik and Kristoufek [Barunik and Kristoufek 2010: 3844-3855].

2. In the following, the $H$ exponents values for 625 - and 1250 -sessions windows will be designated: $H_{625}$ and $H_{125}$, respectively. Calculations of the $H$ exponents were achieved according to the methodology proposed by Siroky. For the first 625 and 1250 prices of a given instrument, the $H_{625}$ and $H_{1250}$ were calculated for the first time $\left(D_{0}\right)^{5}$, after which the calculation window was moved by one session - the next value of the $H_{625}$ and $H_{1250}$ were given for sessions numbers: 2-626 and 2-1251, respectively. Then the calculation window has been moved to the next session. In this way, for the financial instrument listed totally at $K$ sessions, $K-650+1$ exponents of $H_{625}$ and $H-1250+1$ exponents of $H_{1250}$ were computed. In some cases, due to the shorter trading period of a given

${ }^{4}$ For some assets, the last listing in 2019 took place on 30.12.2019, however in the further part of this article the last session of the year will be consistently designated as 31.12.2019.

${ }^{5}$ This date will be denoted as $D_{0}$. Of course, for $H_{1250}$ and $H_{625}$ two different $D_{0}$ dates are obtained. 
instrument, it was not possible to calculate the value of $H_{1250}$ (instruments listed for less than 625 sessions were not included in the analysis). For each of the instruments, the highest and lowest $H$ values were given in the entire analyzed period (for both calculation windows, i.e. 1250 and 625 sessions), the last value $H$, i.e. as at 31.12.2019 (for both calculation windows), as well as the value of $H_{1250}$ five years earlier (i.e. at the end of the session falling 1250 sessions before 31.12.2019) and the value of $H_{625}$ two and a half years earlier (i.e. at the end of the session falling 625 sessions before 31.12.2019). The average values of $H_{1250}$ and $H_{625}$ were also assessed for each analyzed instrument. Cajueiro and Tabak implemented in their model so called,,rolling sample”. In their model: estimates were applied over a given data sample, the statistic were calculated, then the sample was moved up, or ,rolled" one observation forward before the procedure was repeated [Cajueiro and Tabak 2004b: 349-352].

3. For all analyzed financial instruments and for 625 and 1250 sessions (before 31.12.2019) Hurst exponents were calculated with the use of the following methods: Siroky $\left(H_{\text {Siroky }}\right)$, DMA $\left(H_{D M A}\right)$ and DFA $\left(H_{D F A}\right)$. Then the following differences were examined:

$$
\begin{gathered}
H_{\text {Siroky }}-H_{D M A} \\
H_{\text {Siroky }}-H_{D F A}
\end{gathered}
$$

4. The next part of the study compares average $H_{1250}$ and $H_{625}$ for stock indices and FX market, broken down into developed and emerging markets. The average value of the Hurst exponent is understood as the average values of $H_{1250}$ or $H_{625}$ for the time horizon $\left(D_{0}, D_{31122019}\right)^{6}$, calculated for each of the analyzed instruments. In the case of stock indexes, it was taken into account whether the stock index belongs to a developed or an emerging country. In turn, the currency market was divided according to the following method. In the case of the exchange rate XXXYYY, two possibilities can occur. The first that the currencies XXX and YYY belong to developed countries, while the second that the currency XXX comes from a developed country and the currency YYY from an emerging market (other cases were not included in the analysis). The further part of this article assumes that the EUR currency originates from developed countries.

Two rankings have been created for both groups of assets, i.e. stock indices and currencies. The first, in which only the Hurst exponent is taken into account - the lower the Hurst exponent, the time series closer to the anti-persistent series and the higher position of a index in the ranking. This methodology is consisted

${ }^{6} D_{0}$ represents the date for which it was possible to provide the first value of the $H_{1250}$ or $H_{625}$, respectively, according to the methodology described in the second point. $D_{31122019}$ - means the last session in 2019. 
with the ranking proposed by Cajueiro and Tabak [Cajueiro and Tabak 2004a: 349 -352; Cajueiro and Tabak 2005: 671-675].

The second ranking considers the absolute value of the distance between the Hurst exponent and the level of 0.5. The closer the value of such difference is to zero, the more analyzed time series resemble random walk, represented by the value of 0.5 of the Hurst exponent.

In order to obtain a sufficiently large sample, the widest possible time horizon was selected.

5. In the following part of the study, an analysis of the normality of the distribution of average Hurst exponents $\left(H_{1250}\right.$ and $\left.H_{625}\right)$ was developed. The average values were calculated for each of the analyzed financial instruments and then a statistical test was processed in each group (equity indexes and currencies with the division of the latter into: USDXXX, EURXXX, JPYXXX and other currency pairs).

For this purpose, three types of tests were applied: Jarque-Barre (JB), Shapiro-Wilk (SW) and d'Agostion-Pearson (DA).

Two statistic hypotheses were verified:

$\mathbf{H}_{0}$ : In a given segment of the financial market and in the analyzed time window the distribution of average values of Hurst coefficients is a normal distribution.

$\mathbf{H}_{1}$ : In a given segment of the financial market and in the analyzed time window the distribution of average values of Hurst coefficients is not a normal distribution.

\section{RESULTS}

\subsection{Examination of the normality of the distribution of logarithmic rates of return}

As a result of statistical tests, the following results were obtained:

a) Regarding the analysis of the normal distribution of returns and the full time window, the null hypothesis was rejected in favor of the alternative hypothesis for all analyzed financial instruments.

b) Regarding the 625- and 1250-session time window, the results are presented in Table 1. For the 625-session time window, there were no reasons for rejecting the null hypothesis in the case of two stock exchange indices (PSEI and WIG) and sixteen currency pairs (including six from the USDXXX segment, eight from the EURXXX segment and two from the other currency pairs segment). Only for the following currency pairs: USDDKK, USDEUR, EUREGP, EURIDR, EURNAD and EURZAR the p-value was higher than 0.05 in the case of one 
statistical test. In other cases, the p-value was greater than 0.05 for at least two different statistical tests.

In turn, for the 1250-session time window, there was no reason to reject the null hypothesis in the case of only two exchange rates: USDKRW and USDSDG.

Table 1. Financial instruments for which there were no reason to reject the null hypothesis for 625 and 1250 sessions windows. (p-values $>0.05$ in italics)

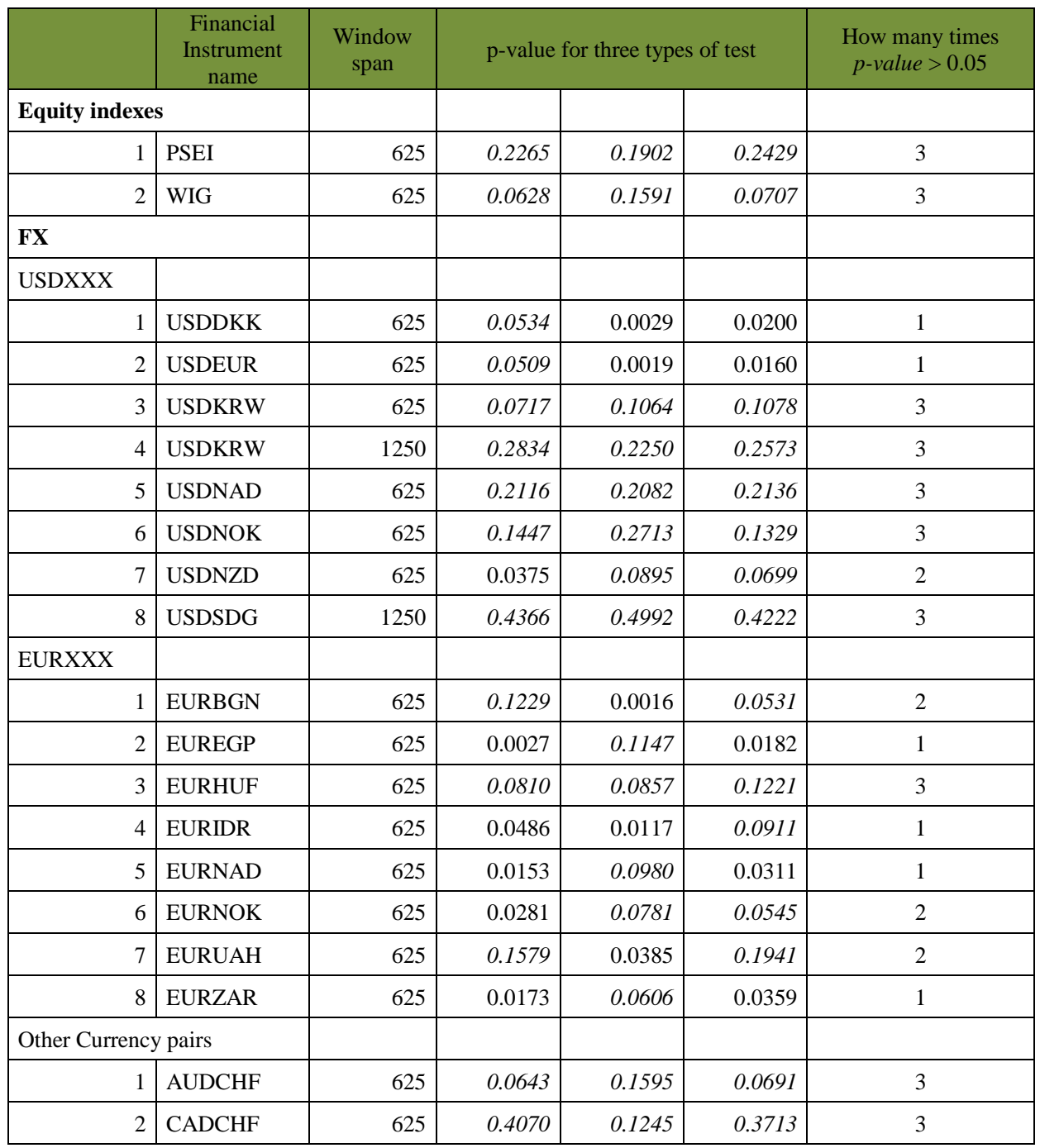

Source: own study. 
The distribution of returns in analyzed financial market segments generally is not a normal distribution. It can also be noted that in the case of a 625-session time window, the number of cases when there were no reason to reject the null hypothesis was definitely higher than for a 1250 -session time window.

\subsection{Comparison of average Hurst exponent $H_{1250}$ and $H_{625}$ for developed and emerging markets}

The average values of $H_{1250}$ exponents were higher than 0.5 for the following percentage of cases: $76.32 \%$ (developed markets) and $88.89 \%$ (emerging markets). In turn, in the case of average values of the $H_{625}$ exponents, the difference between the markets became even more visible, because the percentage of average values of the $H_{625}$ exponents, higher than 0.5 for emerging markets was equal to $94.44 \%$, while for developed markets mounted to $65.79 \%$.

The average $H_{1250}$ values for developed markets oscillated in the range of 0.4727 (FTSE MIBTEL and FTSE MIBTEL) - 0.6596 (NZ50), while for emerging markets in the range: 0.4727 (MEXICIPC) - 0.6409 (SASESLCT). In turn, the average $H_{625}$ values for developed markets belonged to the range: 0.4640 (SMI) - 06594 (NZ50), and for emerging markets to: 0.4609 (MEXICIPC) -0.6615 (SASESLCT).

For the currency market and $H_{1250}<0.5$, the percentage of cases when the second currency of a currency pair belonged to a emerging country and when both came from developed countries, was equal to $19.45 \%$ and $25.93 \%$, respectively. In the group of developed-emerging market pairs, the lowest value was registered for EURRON (0.4258) and the highest for EURBGN (0.7649). In turn, in the group of developed-developed countries' exchanges the lowest and highest value of $H_{1250}$ was registered for AUDCAD (0.4159) and EURCHF (0.6075), respectively. In the case of the condition $H_{625}<0.5$, the percentage of cases when the second currency in the currency pair belonged to the emerging country and when both currencies belonged to developed counties mounted to $22,22 \%$ and $29,79 \%$, respectively. In the group of developed-emerging markets pairs, the lowest value was registered for EURRON (0.4062) and the highest for EURBGN (0.7743). In turn, in the group of developed-developed countries the lowest and highest value of $H_{1250}$ was registered for EURDKK (0.3665) and EURCHF (0.6049), respectively. Thus, for both $H_{1250}$ and $H_{625}$ exponents, the maximum and minimum values were obtained for the same currency pairs of developed and emerging countries, except EURDKK. 


\subsection{Comparison of average Hurst exponent $\boldsymbol{H}_{1250}$ and $\boldsymbol{H}_{625}$ calculated with the following methods: Siroky, DMA and DFA}

For each of the analyzed instrument and $\mathrm{N}=625$ and $\mathrm{N}=1250$, the Hurst exponents were calculated with the use of the following methods: Siroky, DMA, and DFA. The obtained results are presented in Tabels 2, 3 and 4.

Table 2. The percentage of cases when the $H_{\text {Siroky }}$ was greater than that $H_{D F A}$ and $H_{D M A}$, broken down into different market segments $(\mathrm{H}=625$ or $\mathrm{H}=1250)$

\begin{tabular}{|l|c|c|c|c|}
\hline & $\begin{array}{c}\text { Percentage of cases } \\
\text { when }\end{array}$ & $\begin{array}{c}\text { Percentage of cases } \\
\text { when }\end{array}$ & $\begin{array}{c}\text { Percentage of cases } \\
\text { when }\end{array}$ & $\begin{array}{c}\text { Percentage of cases } \\
\text { when }\end{array}$ \\
$H_{\text {Siroky }}-H_{D M A}>0$ & $H_{\text {Siroky }}-H_{D F A}>0$ & $H_{\text {Siroky }}-H_{D M A}>0$ & $H_{\text {Siroky }}-H_{D F A}>0$ \\
$\mathrm{~N}=625$ & $\mathrm{~N}=625$ & $\mathrm{~N}=1250$ & $\mathrm{~N}=1250$ \\
\hline $\begin{array}{l}\text { Equity } \\
\text { indexes }\end{array}$ & 81.25 & 82.16 & 89.36 & 90.25 \\
\hline FX & 86.36 & 87.42 & 93.56 & 92.69 \\
\hline
\end{tabular}

Source: own study.

Table 3. Average values of differences: $H_{\text {Siroky }}-H_{D M A}$ and $H_{\text {Siroky }}-H_{D F A}$. broken down into different market segments $(\mathrm{H}=625$ or $\mathrm{H}=1250)$

\begin{tabular}{|l|c|c|c|c|}
\hline & $\begin{array}{c}\text { Average value of the } \\
\text { difference } \\
H_{\text {Siroky }}-H_{D M A} \\
\mathrm{~N}=625\end{array}$ & $\begin{array}{c}\text { Average value of the } \\
\text { difference } \\
H_{\text {Siroky }}-H_{D F A} \\
\mathrm{~N}=625\end{array}$ & $\begin{array}{c}\text { Average value of } \\
\text { the difference }\end{array}$ & $\begin{array}{c}H_{\text {Siroky }}-H_{D M A} \\
\text { Average value of } \\
\text { the difference }\end{array}$ \\
\hline Equity indexes & 0.0056 & 0.0170 & $\mathrm{~N}=1250$ & $\mathrm{H}=1250$ \\
\hline FX & 0.0276 & 0.0285 & 0.0178 & 0.0141 \\
\hline
\end{tabular}

Source: own study.

In the vast majority of cases, $H_{\text {Siroky }}$ values were slightly higher than $H_{D M A}$ and $H_{D F A}$. The change in the number of sessions from $\mathrm{N}=625$ to $\mathrm{N}=1250$ led to an increase of the percentage of cases when where following inequalities occurred: $H_{\text {Siroky }}-H_{D M A}>0$ and $H_{\text {Siroky }}-H_{D F A}>0$. 
Table 4. Percentage of differences $H_{\text {Siroky }}-H_{D M A}>0$ for different market segments

\begin{tabular}{|l|c|c|c|c|c|c|c|c|c|c|}
\hline & \multicolumn{5}{|c|}{$\mathrm{N}=625$} & \multicolumn{5}{c|}{$\mathrm{N}=1250$} \\
\hline & $<0$ & $(0.00 .1)$ & $(0.1-0.2)$ & $(0.2-0.3)$ & $>0.3$ & $<0$ & $(0.0-0.1)$ & $(0.1-0.2)$ & $(0.2-0.3)$ & $>0.3$ \\
\hline $\begin{array}{l}\text { Equity } \\
\text { indexes }\end{array}$ & 12.83 & 50.97 & 21.41 & 4.09 & 10.71 & 8.60 & 55.25 & 16.64 & 5.00 & 14.51 \\
\hline Currencies & 14.92 & 50.90 & 18.62 & 2.62 & 12.94 & 10.06 & 52.60 & 18.34 & 6.60 & 12.40 \\
\hline
\end{tabular}

Source: own study.

Table 5. Percentage of differences $H_{\text {Siroky }}-H_{D F A}>0$ for different market segments

\begin{tabular}{|l|c|c|c|c|c|c|c|c|c|c|}
\hline & \multicolumn{5}{|c|}{$\mathrm{N}=625$} & \multicolumn{5}{c|}{$\mathrm{N}=1250$} \\
\hline & $<0$ & $(0.0-0.1)$ & $(0.1-0.2)$ & $(0.2-0.3)$ & $>0.3$ & $<0$ & $(0.0-0.1)$ & $(0.1-0.2)$ & $(0.2-0.3)$ & $>0.3$ \\
\hline Equity indexes & 7.46 & 57.91 & 13.74 & 6.17 & 14.72 & 6.93 & 58.96 & 20.83 & 6.96 & 6.32 \\
\hline Currencies & 11.31 & 50.46 & 23.67 & 4.07 & 10.48 & 17.12 & 52.20 & 18.47 & 4.65 & 7.56 \\
\hline
\end{tabular}

Source: own study.

The distribution of differences $H_{\text {Siroky }}-H_{D M A}>0$ and $H_{\text {Siroky }}-H_{D F A}>0$ clearly indicates that their highest percentage was registered in the range $0.0-0.1$ (for all financial instruments). In addition, the percentage of analyzed differences registered in the range $0.0-0.1$ was higher for $\mathrm{N}=1250$ sessions than for $\mathrm{N}=625$ sessions.

\subsection{The first ranking for average Hurst exponents}

\subsubsection{RANKING FOR EQUITY INDEXES}

Rankings of average values $H_{1250}$ and $H_{625}$ are presented in Appendix 2.

For both rankings, the lowest value of the average values $H_{1250}$ and $H_{625}$ was observed for the MEXICIPC index, mounting to 0.4473 and 0.4609 , respectively, while the highest values were noted for index NZ50, and were equal to 0.6596 and 0.6594 , respectively. In the ranking of twenty stock indexes with the lowest average values of $H_{1250}$ and $H_{625}$ exponents, 12 and 13 (respectively), belonged to developed equity markets. What's more interesting, the indexes of countries such as the USA and Germany were not included in the top twenty group. For example DJIA was classified at 56th $\left(H_{1250}\right)$ and 58th $\left(H_{625}\right)$ and DAX at 34th $\left(H_{1250}\right)$ and 23rd $\left(H_{625}\right)$ positions, In turn, the WIG index was ranked at positions 28 th $\left(H_{1250}\right)$ and 37 th $\left(H_{625}\right)$. 


\subsubsection{RANKINGS FOR CURRENCY PAIRS}

In the top twenty ranking of the lowest $H_{1250}$ and $H_{625}$ values, there were 8 currency pairs belonging to developed markets. In addition, the AUDCAD and EURDKK pairs were classified in the highest positions in the ranking for $H_{1250}$, while for $H_{625}$ ranking the order was the reverse. In turn, in the ranking of the twenty highest $H_{1250}$ and $H_{625}$ values there was only one currency pair (EURCHF), when both currencies (EUR and CHF) belong to developed countries.

The highest (the lowest) classified currency pair, when the second currency belongs to the developing country was EURRON (EURBGN). This relationship is true both for $H_{1250}$ and $H_{625}$.

The average value of $H_{1250}$, calculated for pairs in which both currencies belonged to developed countries was equal to 0.5102 . The average value of $H_{1250}$ for the group in which the second currency pertains a developing country, mounted to 0.5467 . For the $H_{625}$ these values were equal to 0.5009 and 0.5380 respectively.

\subsection{The second ranking for average Hurst exponents}

Rankings of average values $H_{1250}$ and $H_{625}$ are presented in Appendix 3.

\subsubsection{RANKING FOR EQUITY INDEXED}

In case of the ranking based on the distance between the Hurst exponent from the level 0.5, for $H_{1250}$ and $H_{625}$, there were 12 and 13 indices, respectively (out of 20) belonging to stock exchanges localized in developed countries. The equity index for New Zealand was classified on the last place in the same ranking. Relatively low positions in the ranking of such indices as NASDAQ, NASDAQ100 or SDAX (all from developed countries) are noteworthy.

\subsubsection{RANKING FOR CURRENCY PAIRS}

In the top twenty currency pairs with the lowest values $\left|H_{1250}-0.5\right|$ and $\left|H_{625}-0.5\right|$, there were 10 and 8 currency pairs, respectively belonging to developed markets. In addition, the JPYAUD and GPBCAD pairs were classified in the highest positions in the ranking for $\left|H_{1250}-0.5\right|$ and $\left|H_{625}-0.5\right|$, respectively. In turn, in the last twenty (i.e. with the highest values of $\left|H_{1250}-0.5\right|$ and $\left.\left|H_{625}-0.5\right|\right)$, there was one currency pair (EURCHF) for $\left|H_{1250}-0.5\right|$ and 3 currency pairs (AIDCAD, EURCHF and EURDKK) for $\left|H_{1250}-0.5\right|$, when both currencies belong to developed countries. 
In the case of $\left|H_{1250}-0.5\right|$ and $\left|H_{625}-0.5\right|$, the highest classified currency pair, when the second currency belongs to the developing country was EURXPD and USDPLN, respectively. The EURBGN currency pair was classified in the last position in rankings for $\left|H_{1250}-0.5\right|$ as well as for $\left|H_{625}-0.5\right|$.

The average value of $\left|H_{1250}-0.5\right|$ calculated for pairs, in which both currencies belonged to developed countries was equal to 0.0258 . In the group when the second currency pertains a developing country, the average value mounted to 0.0568. For the $\left|H_{625}-0.5\right|$, these values were equal to 0.0247 and 0.0554 respectively.

In the case of a cumulative ranking (created for both stock indexes and currency pairs), the extreme values, i.e. the highest and lowest in the first and second ranking, belonged to currency pairs. This fact allows to draw the conclusion that the values of the $H_{1250}$ and $H_{625}$, calculated for the stock indexes, belonged to a narrower range than the same exponents obtained for currency pairs.

\subsection{The relationship between following pairs of Hurst exponents: $\boldsymbol{H}_{625}$ vs $\boldsymbol{H}_{1250}$ and} $\left|H_{1250}-0.5\right|$ vs $\left|H_{625}-0.5\right|$

Relationships between average Hurst exponents $H_{625}$ vs $H_{1250}$ and $\left|H_{1250}-0.5\right|$ vs $\left|H_{625}-0.5\right|$, calculated for stock indices and currency pairs, are shown in Figures no. $1-4$.

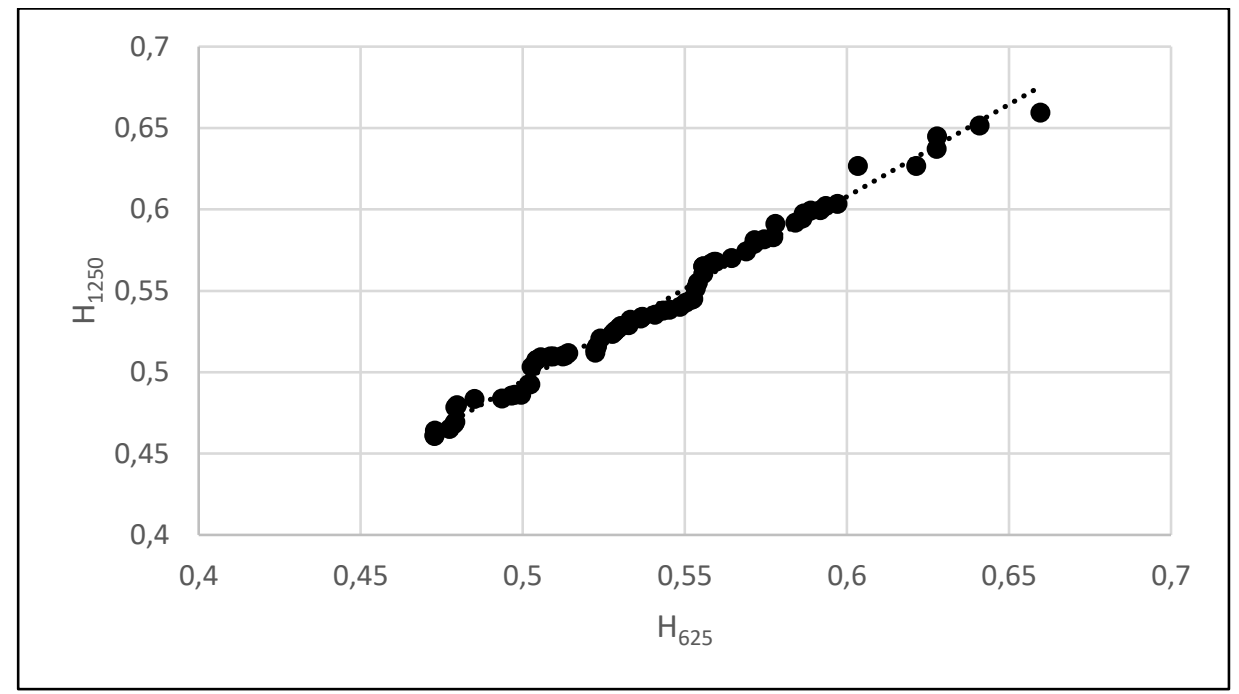

Chart 1. Relationship between the average values $H_{625}$ and $H_{1250}$ for stock indices

Source: own calculations. 


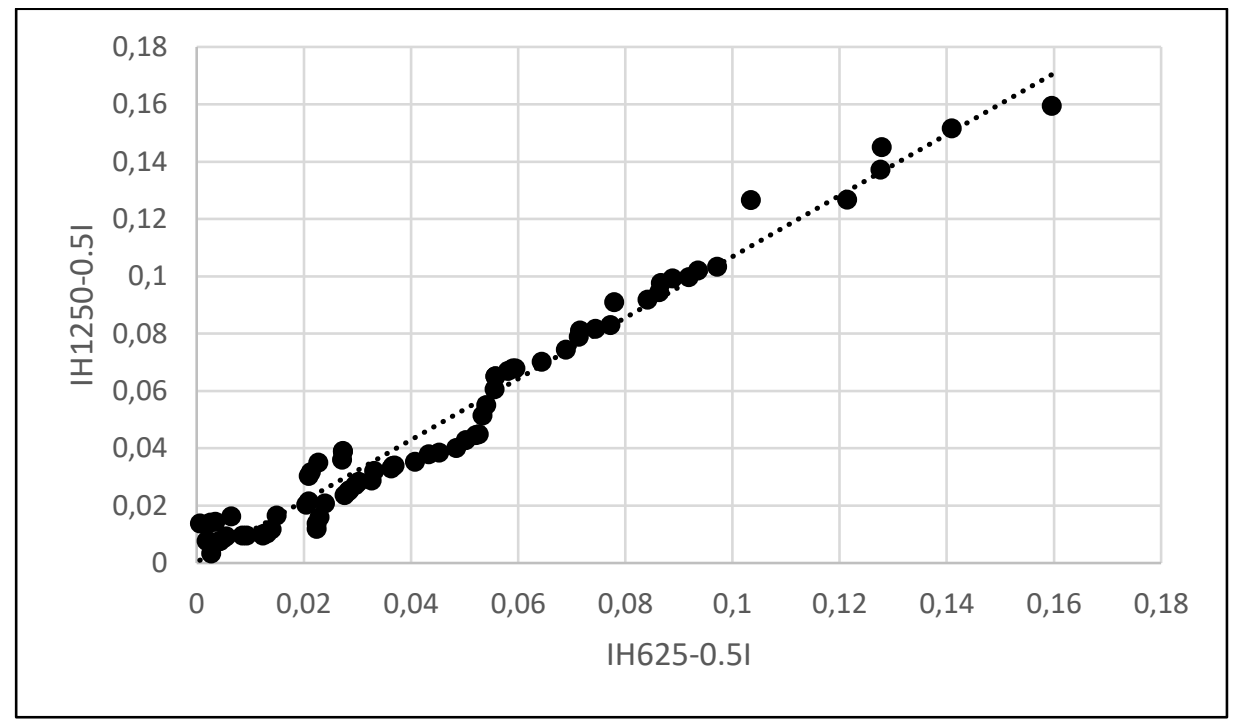

Chart 2. Relationship between the average values $\left|H_{625}-0.5\right|$ and $\left|H_{1250}-0.5\right|$ for stock indices Source: own calculations.

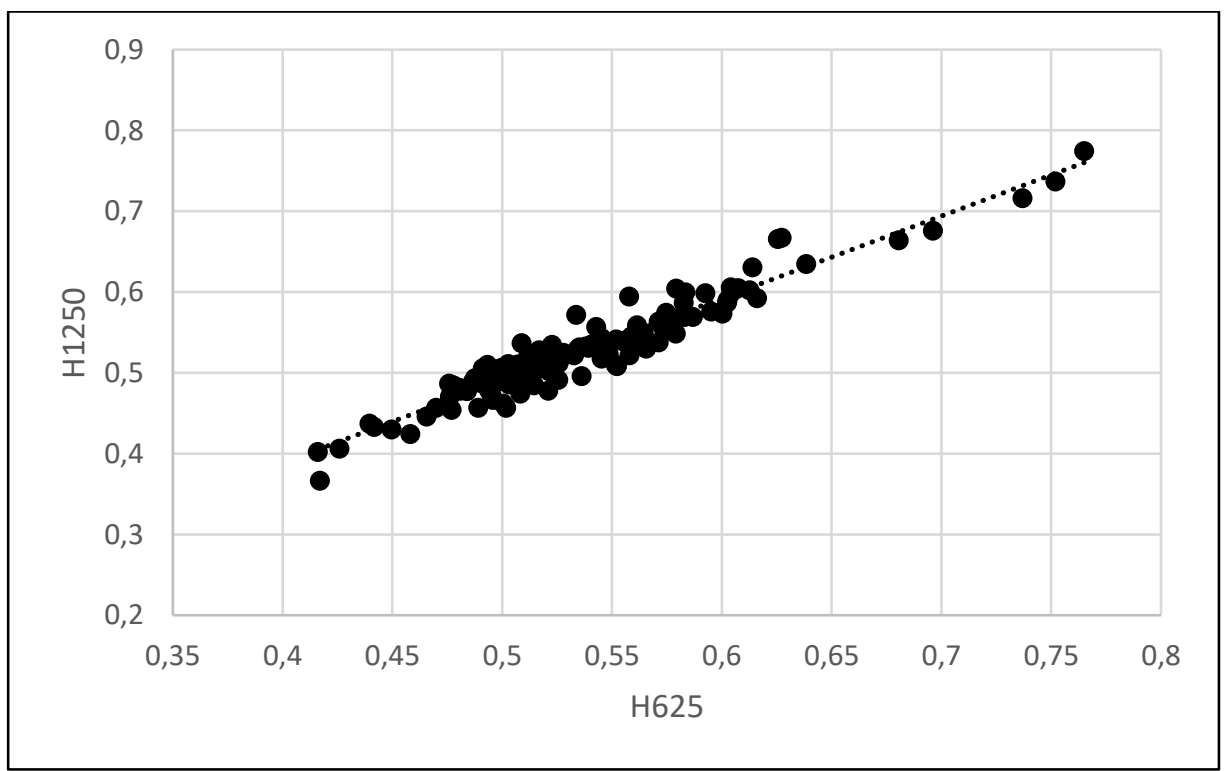

Chart 3. Relationship between the average values $H_{625}$ and $H_{1250}$ for currency pairs Source: own calculations. 


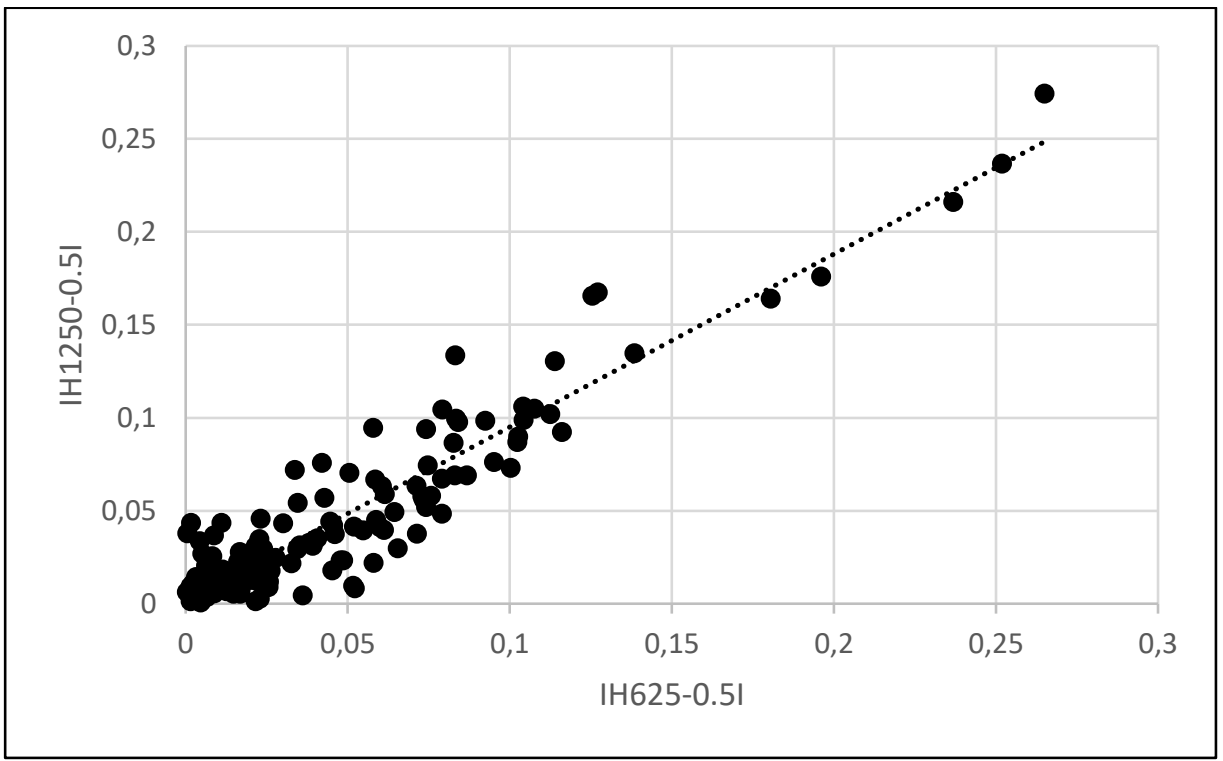

Chart 4. Relationship between the average values $\left|H_{625}-0.5\right|$ and $\left|H_{1250}-0.5\right|$ for currency pairs

Source: own calculations.

Determination coefficients $R^{2}$ calculated for average Hurst exponents $H_{625}$ and $H_{1250}$, as well as for $\left|H_{1250}-0.5\right|$ and $\left|H_{625}-0.5\right|$ mounted to the following values:

a) Equity indexes, $H_{1250}$ vs. $H_{625}: R^{2}=0.98731$

b) Equity indexes, $\left|H_{1250}-0.5\right|$ vs $\left|H_{625}-0.5\right|: R^{2}=0.97150$

c) Currency pairs, $H_{1250}$ vs. $H_{625}: R^{2}=0.92461$

d) Currency pairs, $\left|H_{1250}-0.5\right|$ vs $\left|H_{625}-0.5\right|: R^{2}=0.87406$

In the segment of stock indices, the values of $R^{2}$ coefficients were higher than in the currency segment both for the Hurst exponents, as well as when analyzing Hurst exponents' distance from the level of 0.5, e.g. for $\left|H_{1250}-0.5\right|$ and $\left|H_{625}-0.5\right|$. These results confirm the conclusion obtained in point 3.4.2 on greater compression of the average Hurst exponent values for the capital market index segment than for currencies.

Analysis of average values of $H_{125}$ vs. $H_{625}$ and $\left|H_{1250}-0.5\right|$ vs. $\left|H_{625}-0.5\right|$, broken down into developed and emerging markets, proved that determination coefficients $R^{2}$ are higher in the group of emerging markets - see Table 6. 
Table 6. $R^{2}$ coefficients for average values of $H_{125}$ vs. $H_{625}$ and $\left|H_{1250}-0.5\right|$ vs. $\left|H_{625}-0.5\right|$ broken down into developed and emerging markets

\begin{tabular}{|l|c|c|}
\hline \multicolumn{1}{|c|}{ Stock indexes } & Developed markets & Emerging markets \\
\hline$H_{1250}$ vs. $H_{625}$ & $R^{2}=0.98241$ & $R^{2}=0.99033$ \\
\hline$\left|H_{1250}-0.5\right|$ vs $\left|H_{625}-0.5\right|$ & $R^{2}=0.96438$ & $R^{2}=0.97151$ \\
\hline Currencies & Developed-developed countries & Developed-emerging countries \\
\hline$H_{1250}$ vs. $H_{625}$ & $R^{2}=0.82306$ & $R^{2}=0.93267$ \\
\hline$\left|H_{1250}-0.5\right|$ vs $\left|H_{625}-0.5\right|$ & $R^{2}=0.63984$ & $R^{2}=0.89273$ \\
\hline
\end{tabular}

Source: own calculations.

\subsection{Normal distribution of the average values of the Hurst exponents: $\boldsymbol{H}_{1250}$ and $\boldsymbol{H}_{625}$}

The results obtained are presented in Table 7.

The distribution of average values of Hurst exponents is a normal distribution except for the following groups of assets:

a) USDXXX segment for $H_{1250}$

b) USDXXX segment for $H_{625}$

c) JPYXXX segment for $H_{625}$

In all four cases, the p-value was lower than 0.05 for all three tests (JB, SW and DA). In turn, in the case of the stock indexes and $H_{625}$, the null hypothesis was rejected with the use of SW test, when the p-value was equal to 0.0499 , while in the case of the remaining JB and SW tests, p-value, was higher than 0.05 and amounted to: 0.2079 and 0.1970 respectively.

Table 7. The p-value parameters calculated with the use of normal distribution tests

(JB, SW and DA) for average values of $H_{1260}$ and $H_{625}$ (p-value $<0.05$ in italics).

\begin{tabular}{|l|c|c|c|c|c|c|}
\hline \multirow{2}{*}{ Instrument } & \multicolumn{5}{|c|}{$H_{1250}$} & \multicolumn{3}{c|}{$H_{625}$} \\
\hline Equity indexes & \multicolumn{1}{c|}{$\mathrm{JB}$} & \multicolumn{1}{c|}{ SW } & DA & JB & SW & DA \\
\hline USDXXX & 0.2062 & 0.0730 & 0.1904 & 0.2079 & 0.0499 & 0.1970 \\
\hline JPYXXX & 0.0000 & 0.0000 & 0.0000 & 0.0000 & 0.0001 & 0.0000 \\
\hline Other currency pairs & 0.1543 & 0.4084 & 0.0638 & 0.0305 & 0.0227 & 0.0066 \\
\hline
\end{tabular}

Source: own study. 


\section{CONCLUSIONS}

The main conclusions obtained in the study may be formulated as follows:

a) The percentage of cases, when the condition $H_{1250}>0.5$ is met, was higher for emerging than for developed markets. This relationship was even more apparent for $H_{625}$. Given the relationship between the fractal dimension and the Hurst exponent, this means that investment risk in emerging markets was lower than in developed markets and this tendency has increased in the past two and a half years (assuming that the fractal dimension is a risk measure).

b) The Hurst coefficient values calculated with the use of Siroky method are similar to the results obtained on the basis of DFA and DMA methods. The differences in the obtained values of the Hurst exponents, calculated with the use of three different methods, result from the approximation of MTR applied in the Siroky method. As the number of sessions increases, the differences in Hurst coefficient values calculated on the basis of Siroky's method are similar to those obtained with the application of the DMA and DFA methods.

c) The average values of Hurst exponents for the capital market indexes were more compressed than those calculated for currency pairs.

d) In the case of the forex market and the first ranking, among the currency pairs with the lowest $H$ values, there were pairs in which both currencies belong to developed countries, as well as pairs, ich which the second currency derived from the emerging market. In turn, among currency pairs with the highest $H$ values dominated currency pairs in which the second currency belonged to the emerging market country.

e) Analyzing the distribution of developed-developed and developed-emerging currency pairs in the first ranking, it can be concluded that these exchange rates in the developed-developed group are more effective than in the case of the second group. However, it should be remembered that this is a general conclusion, and the effectiveness of the exchange rate of a given currency pair is its individual feature.

f) With few exceptions, the distribution of average values of Hurst exponents is a normal distribution.

The obtained results regarding the increase in investment risk proved conclusions presented by Przekota, who verified the hypothesis the lower values of the fractal dimension are consistent with lower risk, and higher values of the fractal dimension with higher risk [Przekota 2012: 186-187].

The presented results are in line with those published in relation to the S\&P 500 index by Alvarez-Ramirez et al. and Dominique and Rivera, and in the case of the NASDAQ index by Glenn [Alvarez-Ramirez et al. 2008: 6159-6169; Dominique and Rivera 2011: 1-6; Glenn 2007]. The results also confirm the conclusions obtained by Huang and Yang in the process of analyzing the Hurst 
exponents for the indices: DJIA, NASDAQ and S\&P 500, as well as results revealed by Henry for DAX, TOPIX and Nikkei 225 [Huang and Yang 1999; Henry 2002: 725-729].

On the other hand, the obtained results are in contradiction to the conclusions published by: Onali and Goddard for the FTSEMIBTEL and PX indices, by Henry for the Kospi index, Berg and Lyhagen for OMX Stockholm Index, by Barkoulas and Baum for three indices: DJIA, NASDAQ and S\&P 500 and by Cajueiro and Tabak for the MEXIPC and IPC indexes [Onali and Goddard 2010; Henry 2002: 725-729; Barkoulas and Baum 1996: 253-259; Cajueiro and Tabak 2004b: 349 -352; Cajueiro and Tabak 2005: 671-675]. In the case of Latin American stock exchange indices, the two Mexican stock exchange indices MEXIPC and IPC were ahead of the highest qualified Asian index, i.e. Kospi. The latter was classified in the first ranking at the higher position than the Bovespa index. It should be noted, however, that only a few Latin American stock exchange indices were applied in the study.

In the case of the S\&P 500 index, the obtained results contradict the conclusions drawn from the work of Granger and Ding, Granger and Hyung, as well as Lo and Jacobsen [Granger and Ding 1995: 67-91; Granger and Hyung 2004: 399-421; Lo 2004: 15-29; Jacobsen 1995: 37-52].

The received results regarding the percentage of cases when the average $H$ values were higher than 0.5 for emerging markets confirm those by Di Mateo et al. and by Kapecka [Di Matteo et al. 2003: 183-188; Kapecka 2015: 59-75]. In the part regarding the percentage of cases when the average $H$ values were higher than 0.5 for developed markets, the obtained results are consistent with the research of Kapecka and Barunik and Kristoufek, while contradicting the conclusions presented by Mateo et al. as well as by Lipka and Los [Kapecka 2015: 59-75; Barunik and Kristoufek 2010: 3844-3855; Di Mateo et al. 2003: 183-188; Lipka and Los 2003]. However, it should be remembered that the first research concerns only four stock indexes. In addition, in the current study the average values of the Hurst exponent were taken into account, while in both cited papers only one Hurst exponent was calculated for each of the analyzed stock indices. The results of the study referring to the persistence of Hurst exponents for Latin American markets are consistent with the conclusions published by Kyawa et al. [Kyaw et al. 2004].

On the basis of the presented research it was found that the periods with large Hurst exponents can be predicted more accurately than those with $H$ values close to random series. This suggests that analyzed markets (equity and forex) are not totally random in all periods. Some periods are characterized by strong trend structure and this structure can be used to open and close investment positions. 


\section{BIBLIOGRAPHY}

Abry P., Veitch D., 1998, Wavelet Analysis Of Long-Range Dependent Traffic, „IEEE/ACM Transactions Information Theory", vol. 1(44).

Alessio E., Carbone A., Castelli G., Frappietro V., 2002, Second-Order Moving Average And Scaling Of Stochastic Time Series, „European Physical Journal”, vol. 2(27).

Alvarez-Ramirez J., Alvarez J., Rodriguez E., Fernandez A., 2008, Time-Varying Hurst Exponent For Us Stock Markets, „Physica A”, vol. 24.

Alvarez-Ramirez J., Cisneros M., Ibarra-Valdez C., Soriano A., 2002, Multifractal Hurst Analysis Of Crude Oil Prices, ,Physica A”, vol. 313.

Barkoulas J., Baum C., 1996, Long-Term Dependence In Stock Returns, „Economics Letters”, vol. 53.

Barkoulas J., Labys W., Onochie J., 1997, Fractional Dynamics In International Commodity Prices, „Journal of Futures Markets”, vol. 17(2).

Barunik J., Kristoufek L., 2010, On Hurst Exponent Estimation Under Heavy-Tailed Distributions, „Physica A”, vol. 389.

Batten J., Ellis C., Fetherston T., 2003, Return Anomalies On The Nikkei: Are They Statistical Illusions?, http://ssrn.com/abstract=396680 [access 12.03.2020].

Berg L., Lyhagen J., 1996, Short And Long Run Dependence In Swedish Stock Returns, http://ssrn.com/abstract=2270 [access 12.03.2020].

Bunde A., Havlin S., 1995, A brief introduction to fractal geometry, [in] A. Bunde, S. Havlin [ed.], Fractal and disordered systems, Springer-Verlag, Berlin.

Cajueiro D., Tabak B., 2004a, Ranking Efficiency For Emerging Markets, „Chaos, Solitons and Fractals", vol. 22.

Cajueiro D., Tabak B., 2004b, The Hurst Exponent Over Time: Testing The Assertion That The Emerging Markets Are Becoming More Efficient, „Physica A”.

Cajueiro D., Tabak B., 2005, Ranking Efficiency For Emerging Markets II, „Chaos, Solitons and Fractals", vol. 23.

Caporale G., Gil_Alana L., Plastun A., Makarnko L., 2016, Long Memory In The Ukrainian Stock Market And Financial Crises, ,Journal of Economics and Finance”, vol. 40.

Caporale G., Gil-Alana L., Plastun A., 2018, Is Market Fear Persistent? A Long-Memory Analysis, „Finance Research Letters”, vol. 27.

Caraiani P., 2012, Evidence Of Multifractality From Emerging European Stock Markets, „PLoS ONE", vol. 7, e40693.

Cheung Y., Lai K., 1995, A Search For Long-Range Dependence In International Stock Market Returns, „Journal of International Money and Finance”, vol. 14(4).

Chow K., Ming-Shium P., Ryoichi S., 1996, On The Long-Run Or Short-Term Dependence In Stock Prices: Evidence From International Stock Markets, „Review of Quantitative Finance and Accounting", vol. 6(2).

Corazza M., Malliaris A., 2002, Multifractality In Foreign Currency Markets, „Multinational Finance Journal", vol. 6.

Costa R, Vasconcelos G., 2003, Long-Range Correlations And Nonstationarity In The Brazilian Stock Market, „Physica A”, vol. 329(1-2).

Crato N., Ray B., 1999, Memory in returns and volatilities of commodity futures' contracts, http://citeseerx.ist.psu.edu/viewdoc/summary?doi=10.1.1.42.6774 [access 12.03.2020].

Czarnecka A., Wilimowska Z., 2018, Hurst exponent as a risk measurement on the capital market, [in] J. Świątek, L. Borzemski, Z. Wilimowska, Information Systems Architecture and Technology: Proceedings of 38th International Conference on Information Systems Architecture and Technology, ISAT 2017, 2018. Pt. 2,Springer International Publishing, Warszawa. 
Da Silva S., Matsushita R., Gleria I., Figueiredo A., 2007, Hurst Exponents, Power Laws, And Efficiency In The Brazilian Foreign Exchange Market, „Economics Bulletin”, vol. 7(1).

Di Matteo T., Aste T., Dacorogna M., 2003, Scaling Behaviors Indifferently Developed Markets, „Physica A”, vol. 324.

Dominique C., Rivera S., 2011, Mixed Fractional Brownian Motion, Short And Long-Term Dependence And Economic Conditions: The Case Of The S\&P 500 Index, ,International Business Management", vol. 3.

Domino K., 2011, The Use Of The Hurst Exponent To Predict Changes In Trend On The Warsaw Stock Exchange, „Physica A”, vol. 390.

Ehlers J., 2005, Fractal Adaptive Moving Average, „Technical Analysis of Stock \& Commodities”, vol. 10(23).

Ehlers J., Way R., 2010, Fractal Dimension As A Market Mode Sensor, „Technical Analysis of Stock \& Commodities", vol. 6(28).

Einstein A., 1908, Elementare theorie der Brownschen bewungen, „Zeitschrift für Elektrochemie und angewandte physikalische Chemie", vol. 14(50).

Ferreira P., 2018, Long-Range Dependence Of Eastern-European Stock Markets: A Dynamic Detrended Analysis, „Physica A”, vol. 505.

Glenn L., 2007, On Randomness And The NASDAQ Composite", Working Paper, http://ssrn.com/abstract=1124991 [access 12.03.2020].

Granger C., Ding Z., 1995, Some Properties Of Absolute Returns, A Alternative Measure Of Risk, „Annales d'Economie et de Statistique”, vol. 40.

Granger C., Hyungh H., 2004, Occasional Structural Breaks And Long Memory With An Application To S\&P 500 Absolute Stock Returns, ,Journal of Empirical Finance”, vol. 11.

Greene M., Fielitz B., 1977, Long-term dependence in common stock returns, „Journal of Financial Economics", vol. 4.

Henry O., 2002, Long Memory In Stock Returns, Some International Evidence, „Applied Financial Economics", vol. 12.

Hiemstra C., Jones D., 1997, Another Look At Long Memory In Common Stock Returns, „Journal of Empirical Finance", vol. 4(4).

Hja S., Lin Y., 2007, $R S$ Analysis Of China Securities Markets, „Tsinghua Science and Technology", vol. 8(5).

Huang B., Yang C., 1999, An Examination Of Long-Term Memory Using The Intraday Stock Returns, Working Paper, Clarion University of Pennsylvania.

Hurst H., 1951, Long Term Storage Capacity Of Reservoirs, „Transactions of American Society of Civil Engineers", vol. 116.

Jacobsen B., 1995, Are Stock Returns Long Term Dependent? Some Empirical Evidence, „Journal of International Financial Markets, Institutions and Money", vol. 5(2/3).

Jagric T., Podobnik K., Kolanovic M., 2005, Does The Efficient Market Hypothesis Hold? Evidence From Six Transition Economies, „Ester European Economics”, vol. 43.

Jud S., 2017, Conquering The Seven Faces Of Risk, FinTech Press, Seattle.

Kale M., Butar F., 2011, Fractal Analysis Of Time Series And Distribution Properties Of Hurst Exponent, ,Journal of Mathematical Sciences \& Mathematics Education”, vol. 5(1).

Kantelhardt J., Zschiegner S., Koscielny-Bunde E., Budne A., Havlin S., Stanley E., 2002, Multifractal Detrended Fluctuation Analysis Of Nonstationary Time Series, „Physica A”, vol. 316(1-4).

Kapecka A., 2015, Analiza porównawcza wybranych indeksów giełdowych rynków dojrzatych $i$ wschodzacych z wykorzystaniem wyktadnika Hursta, „Acta Universitatis Nicolai Copernici, Ekonomia", vol. 1(46).

Kim K., Yoon S., 2004, Multifractal Features Of Financial Markets, „Physica A”, vol. 344(1). 
Kowgier H., 2009, Kilka uwag o wymiarze fraktalnym Minkowskiego oraz wyktadniku Hursta na Giełdzie Papierów Wartościowych, „Studia i Prace Wydziału Nauk Ekonomicznych i Zarządzania", vol. 15.

Kristoufek L., Vosvdra M., 2013, Measuring capital market efficiency: Global and local correlation structure, „Physica A”, vol. 392.

Kyaw N., Los C., Zong S., 2004, Persistence Characteristics Of Latin American Financial Markets, Kent State University Finance Working Paper, https://ssrn.com/abstract=298745 [access 12.03.2020].

Lento C., 2009, A Synthesis Of Technical Analysis And Fractal Geometry - Evidence From The Dow Jones Industrial Average Components, http://ssrn.com/abstract=1263615 [access 12.03.2020].

Lipka J., Los C., 2003, Long-Term Dependence Characteristics Of European Stock Indices, Economics Working Paper Archive, EconWPA, Finance Nº409044.

Lo A., 1991, Long-Term Memory In Stock Market Prices, „Econometrica”, vol. 59.

Lo A., 2004, The Adaptive Markets Hypothesis: Market Efficiency Form An Evolutionary Perspective, ,Journal of Portfolio Management”, vol. 30, pp. 15-29.

Los C., Yalamova R., 2006, Multi-Fractal Spectral Analysis Of The 1987 Stock Market Crash, „International Research Journal of Finance and Economics”, vol. 1, 4, pp. 106-133.

Lu Y., Perron P., 2010, Modeling And Forecasting Stock Return Volatility Using A Random Level Shift Model, „Journal of Empirical Finance”, vol. 17, pp. 138-156.

Mandelbrot B., Wallis J., 1968, Joseph And Operational Hydrology, Water-Resources Research, no. 4.

Mantenga R., Stanley H., 1995, Scaling Behavior In The Dynamics Of An Economic Index, „Nature”, vol. 376, pp. 46-49.

Mastalerz-Kodzis A., 2003, Modelowanie procesów na rynku kapitatowym za pomoca multifraktali, Wydawnictwo Akademii Ekonomicznej w Katowicach, Katowice.

McKenzie M., 2001, Non-Periodic Australian Stock Market Cycles: Evidence From Rescaled Range Analysis, „Economic Record”, vol. 77, pp. 393-406.

Mulligan R., 2000, A Fractal Analysis Of Foreign Exchange Markets, „International Advances in Economic Research", vol. 6(1).

Muzy J., Barcy E., Arneodo A., 1994, The Multifractal Formalism Revisited With Wavelets, „National Journal of Bifurcation and Chaos”, vol. 2(2).

Mynhardt R., Plastun A., Makarenko I., 2014, Behavior Of Financial Markets Efficiency During The Financial Market Crisis: 2007-2009. Munich Persona RePEc Archive (MPRA), no. 58942, https://mpra.ub.uni-muenchen.de/58942/ [access 12.03.2020].

Onali E., Goddard J., 2010, Are European Equity Markets Efficient? New Evidence From Fractal Analysis", http://ssrn.com/abstract=1805044 [access 12.03.2020].

Opong K., Mulholland G., Fox A., Farahmand K., 1999, The Behaviour Of Some UK Equity Indices: An Application Of Hurst And BDS Tests, „Journal of Empirical Finance”, vol. 6.

Orzeszko W., 2010, Fractal Dimension Of Time Series As A Measure Of Investment Risk, „Acta Universitatis Nicolai Copernici. Ekonomia", vol. 41.

Peng C., Buldyrev S., Havlin S., Simons M., Goldberger A., 1994, Mosaic Organization Of DNA Nucleotides, „Physica Review E”, vol. 49(2).

Peters E., 1991, Chaos And Order In Capital Markets, John Wiley \& Sons, New York.

Peters E., 1994, Practical Market Analysis, Applying Chaos Theory To Investment And Economics, John Wiley \& Sons, New York.

Peters E., 1997, Teoria chaosu i rynki finansowe, WIG-PRESS, Warszawa.

Przekota G., 2012, Szacowanie ryzyka zmian cen akcji metoda podziału pola, „Problemy Zarządzania", vol. 4(10). 
Raimundo M., Okamoto J., 2018, Application Of Hurst Exponent (H) And The R/S Analysis In The Classification Of FOREX Securities, „International Journal of Modelling and Optimization”, vol. 8(2).

Serletis A., Rosenberg A., 2009, Mean Reversion In The US Stock Market, „Chaos, Solitons and Fractals", vol. 40.

Siroky M., 2017, Estimating The Fractal Dimension On Stock Prices, „Technical Analysis of Stock \& Commodities", vol. 12(35).

Voss R., 1991, Random Fractal Forgeries, [in:] R. Earnshaw (ed.), Fundamental Algorithms For Computer Graphicpp, Springer, Berlin.

Weron A., Weron R., 1998, Inżyniera finansowa, Wydawnictwo Naukowo-Techniczne, Warszawa. Wilder W., 1978, New Concept In Technical Trading Systems, Trend research, Washington. [www1] www.ion.researchsystems.com/IONScript/wavelet/website [access 12.01.2020]. 


\section{APPENDIXES}

\section{Appendix 1}

The list of analyzed financial assets and the dates of their first listing disclosed in the database (portals: stooq.pl and bossa.pl)

\begin{tabular}{|c|c|c|c|c|c|c|}
\hline No. & Equity indexes & $\begin{array}{c}\text { First } \\
\text { quotation }\end{array}$ & \multicolumn{2}{|c|}{ FX market } & \multicolumn{2}{|c|}{ FX market } \\
\hline 1 & AEX & 04.01 .1983 & USDXXX & $\begin{array}{l}\text { First } \\
\text { quotation }\end{array}$ & EURSEK & 04.01 .1971 \\
\hline 2 & ALL ORDINARIES & 31.10 .1989 & USDAUD & 04.01 .1971 & EURTHB & 04.01 .1993 \\
\hline 3 & AMEX & 03.01 .1995 & USDBGN & 23.10 .1995 & EURTRY & 02.01 .1991 \\
\hline 4 & $\begin{array}{l}\text { ATHEX } \\
\text { COMPOSITE }\end{array}$ & 02.01 .1987 & USDBRL & 02.01 .1995 & EURTWD & 02.01 .1991 \\
\hline 5 & ATX & 11.11 .1992 & USDCAD & 04.01 .1971 & EURUAH & 02.09 .1996 \\
\hline 6 & BEL20 & 29.10 .1991 & USDCHF & 04.01 .1971 & EURXAG & 02.01 .1991 \\
\hline 7 & BET & 31.10 .2000 & USDCLP & 25.10 .1993 & EURXAU & 02.01 .1991 \\
\hline 8 & BIST 100 & 03.01 .1988 & USDCNY & 09.01 .1984 & EURXDR & 02.01 .1991 \\
\hline 9 & BOVESPA & 02.01 .1995 & USDCZK & 23.10 .1995 & EURXPD & 02.01 .1991 \\
\hline 10 & BSE SENSEX & 03.04 .1979 & USDDKK & 02.01 .1984 & EURXPT & 02.01 .1991 \\
\hline 11 & BSHARES & 11.05 .1998 & USDEGP & 16.11.1995 & EURZAR & 02.01 .1991 \\
\hline 12 & BUENOS & 08.10 .1996 & USDEURO & 04.01 .1971 & JPYXXX & $\begin{array}{l}\text { First } \\
\text { quotation }\end{array}$ \\
\hline 13 & BUX & 02.01 .1991 & USDGBP & 04.01 .1971 & JPYCNY & 02.01 .1991 \\
\hline 14 & $\mathrm{CAC} 40$ & 02.01 .1969 & USDHKD & 09.01 .1984 & JPYHKD & 02.01 .1991 \\
\hline 15 & China A50 & 19.05 .2010 & USDHRK & 23.10 .1995 & JPYIDR & 25.10 .1993 \\
\hline 16 & CSE ALL SHARES & 13.07.2000 & USDHUF & 23.10 .1995 & JPYILS & 25.10 .1993 \\
\hline 17 & DAX & 28.09 .1959 & USDIDR & 25.10 .1993 & JPYINR & 02.01 .1991 \\
\hline 18 & DJIA & 27.05 .1896 & USDILS & 25.10 .1993 & JPYKRW & 02.01 .1991 \\
\hline 19 & DJTA & 26.10 .1896 & USDINR & 02.01 .1973 & JPYMYR & 02.01 .1991 \\
\hline 20 & DJUA & 02.01 .1929 & USDISK & 23.10 .1995 & JPYNZD & 02.01 .1991 \\
\hline 21 & EOE & 02.01 .1995 & USDJPY & 21.01 .1974 & JPYPHP & 25.10 .1993 \\
\hline 22 & EURO STOXX 50 & 15.08 .2011 & USDKRW & 13.04 .1981 & JPYSGD & 02.01 .1991 \\
\hline 23 & FTSE 100 & 22.10 .1992 & USDMXN & 09.11 .1989 & JPYTHB & 04.01 .1993 \\
\hline 24 & FTSE MIBTEL & 02.01 .1998 & USDMYR & 08.01 .1990 & JPYTWD & 02.01 .1991 \\
\hline 25 & FTSE250 & 31.12 .1985 & USDNAD & 09.01 .1984 & JPYBGN & 23.10 .1995 \\
\hline 26 & HANG SENG & 24.11 .1969 & USDNOK & 04.01 .1971 & JPYCHF & 04.01 .1971 \\
\hline 27 & HEX & 02.01 .1995 & USDNZD & 04.01 .1971 & JPYCZK & 23.10 .1995 \\
\hline 28 & IBEX 35 & 05.01 .1987 & USDPHP & 25.10 .1993 & JPYDKK & 02.01 .1991 \\
\hline 29 & IDX COMPOSITE & 09.04 .1990 & USDPLN & 16.05 .1991 & JPYGBP & 04.01 .1971 \\
\hline 30 & IPC & 08.11 .1991 & USDRON & 23.10 .1995 & JPYHRK & 23.10 .1995 \\
\hline 31 & IPSA & 02.01 .1987 & USDRUB & 23.10 .1995 & JPYHUF & 23.10 .1995 \\
\hline 32 & JCI & 04.04 .1983 & USDSDG & 02.01 .1981 & JPYISK & 23.10 .1995 \\
\hline 33 & KLCI & 03.01 .1977 & USDSEK & 04.01 .1971 & JPYNOK & 02.01 .1991 \\
\hline 34 & KOSPI & 01.05 .1981 & USDTHB & 04.01 .1993 & JPYPLN & 16.05 .1991 \\
\hline
\end{tabular}




\begin{tabular}{|c|c|c|c|c|c|c|}
\hline 35 & MDAX & 29.02 .1996 & USDTRY & 02.01 .1984 & JPYRON & 23.10 .1995 \\
\hline 36 & MERVAL & 16.05 .1988 & USDTWD & 02.01 .1984 & JPYRUB & 23.10 .1995 \\
\hline 37 & MEXICIPC & 20.12 .1993 & USDUAH & 02.09 .1996 & JPYSEK & 04.01 .1971 \\
\hline 38 & MOEX & 23.09 .1997 & USDXAG & 09.01 .1984 & JPYTRY & 02.01 .1991 \\
\hline 39 & NASDAQ & 03.05 .1971 & USDXAU & 09.01 .1984 & JPYUAH & 02.09 .1996 \\
\hline 40 & NASDAQ 100 & 01.10 .1985 & USDXDR & 02.01 .1991 & JPYBRL & 03.01 .1995 \\
\hline 41 & NIFTY 50 & 06.11 .1995 & USDXPD & 09.01 .1984 & JPYCAD & 04.01 .1971 \\
\hline 42 & NIKKEI & 01.06 .1949 & USDXPT & 09.01 .1984 & JPYCLP & 25.10 .1993 \\
\hline 43 & NZ 50 & 03.01 .2001 & USDZAR & 04.01 .1971 & JPYMXN & 02.01 .1991 \\
\hline 44 & OMX RIGA & 03.01 .2000 & EURXXX & $\begin{array}{l}\text { First } \\
\text { quotation }\end{array}$ & JPYEGP & 16.11.1995 \\
\hline 45 & OMX S30 & 01.10 .1986 & EURAUD & 02.01 .1980 & JPYNAD & 02.01 .1991 \\
\hline 46 & $\begin{array}{l}\text { OMX } \\
\text { STOCKHOLM }\end{array}$ & 30.09 .1986 & EURBGN & 23.10 .1995 & JPYZAR & 02.01 .1991 \\
\hline 47 & OMX TALLINN & 03.01 .2000 & EURBRL & 03.01 .1995 & JPYXAG & 02.01 .1991 \\
\hline 48 & OMX VILNIUS & 03.01 .2000 & EURCAD & 04.01 .1971 & JPYXAU & 02.01 .1991 \\
\hline 49 & OSE ALL & 03.01 .1983 & EURCHF & 04.01 .1971 & JPYXPD & 02.01 .1991 \\
\hline 50 & PSEI & 02.01 .1986 & EURCLP & 25.10 .1993 & JPYXPT & 02.01 .1991 \\
\hline 51 & PSI 20 & 03.01 .1983 & EURCNY & 02.01 .1991 & JPYXDR & 02.01 .1991 \\
\hline 52 & PX & 07.09 .1993 & EURCZK & 23.10 .1995 & JPYAUD & 02.01 .1984 \\
\hline 53 & RTSI & 04.09 .1995 & EURDKK & 02.01 .1991 & $\begin{array}{l}\text { Other } \\
\text { Currency } \\
\text { Pairs } \\
\end{array}$ & $\begin{array}{l}\text { First } \\
\text { quotation }\end{array}$ \\
\hline 54 & RUSSEL & 22.10 .2001 & EUREGP & 16.11.1995 & AUDCHF & 02.01 .1980 \\
\hline 55 & S\&P ASX 200 & 01.06 .1992 & EURGBP & 04.01 .1971 & AUDNZD & 02.01 .1991 \\
\hline 56 & $\begin{array}{l}\text { S\&P TSX } \\
\text { COMPOSITE }\end{array}$ & 03.01 .1977 & EURHKD & 02.01 .1991 & AUDCAD & 02.01 .1980 \\
\hline 57 & SASESLCT & 02.01 .2003 & EURHRK & 23.10 .1995 & CADCHF & 04.01 .1971 \\
\hline 58 & SAX & 03.07 .1995 & EURHUF & 23.10 .1995 & GBPAUD & 02.01 .1980 \\
\hline 59 & SDAX & 15.03.1999 & EURIDR & 25.10 .1993 & GBPCAD & 04.01 .1971 \\
\hline 60 & SET & 05.01 .1982 & EURILS & 25.10 .1993 & GBPCHF & 04.01 .1971 \\
\hline 61 & $\begin{array}{l}\text { Shanghai } \\
\text { Composite }\end{array}$ & 20.12 .1990 & EURINR & 02.01 .1991 & GBPPLN & 16.05 .1991 \\
\hline 62 & SMI & 01.07 .1988 & EURISK & 23.10 .1995 & NZDJPY & 02.01 .1991 \\
\hline 63 & SOFIX & 26.11 .2001 & EURJPY & 04.01 .1971 & GBPNZD & 09.01.1984 \\
\hline 64 & SP500 & 17.02 .1885 & EURKRW & 13.04 .1981 & AUDPLN & 16.05 .1991 \\
\hline 65 & STRAITS TIMES & 28.12 .1987 & EURMXN & 02.01 .1991 & CHFPLN & 16.05 .1991 \\
\hline 66 & TA 35 & 20.10 .1992 & EURMYR & 02.01 .1991 & & \\
\hline 67 & TAIEX & 05.01 .1995 & EURNAD & 02.01 .1991 & & \\
\hline 68 & TECDAX & 16.09.1999 & EURNOK & 02.01 .1991 & & \\
\hline 69 & TOPIX & 22.10 .2001 & EURNZD & 02.01 .1991 & & \\
\hline 70 & TSE300 & 15.08 .1989 & EURPHP & 25.10 .1993 & & \\
\hline 71 & UK 100 & 13.11 .1935 & EURPLN & 16.05 .1991 & & \\
\hline 72 & UX & 03.11 .1997 & EURRON & 23.10 .1995 & & \\
\hline 73 & WIG & 16.04 .1991 & EURRUB & 23.10 .1995 & & \\
\hline 74 & XU 100 & 02.01 .1990 & EURSDG & 02.01 .1981 & & \\
\hline
\end{tabular}

Source: own calculations. 


\section{Appendix 2}

First and the second ranking of equity indexes

Indexes from developed countries marked in bold

\begin{tabular}{|c|c|c|c|c|c|c|c|c|}
\hline \multicolumn{5}{|c|}{ First index ranking } & \multicolumn{4}{|c|}{ Second index ranking } \\
\hline $\begin{array}{l}\text { Ran- } \\
\text { king }\end{array}$ & Index & $\begin{array}{c}\text { Average } \\
\text { value of } \\
H_{1250} \\
\end{array}$ & Index & $\begin{array}{c}\text { Average } \\
\text { value of } \\
H_{625}\end{array}$ & Index & $\left|H_{1250}-0.5\right|$ & Index & $\left|H_{625}-0.5\right|$ \\
\hline 1 & MEXICIPC & 0.4727 & MEXICIPC & 0.4609 & S\&P ASX 200 & 0.0006 & $\mathrm{PX}$ & 0.0138 \\
\hline 2 & FTSE MIBTEL & 0.4727 & IPC & 0.4612 & BIST 100 & 0.0018 & \begin{tabular}{|l|} 
ALL \\
ORDINARIES
\end{tabular} & 0.0076 \\
\hline 3 & IPC & 0.4729 & SMI & 0.464 & XU 100 & 0.0023 & KLCI & 0.0075 \\
\hline 4 & $\begin{array}{l}\text { EURO STOXX } \\
\mathbf{5 0}\end{array}$ & 0.4773 & FTSE MIBTEL & 0.465 & MOEX & 0.0025 & OMX S30 & 0.014 \\
\hline 5 & IBEX 35 & 0.4787 & \begin{tabular}{|l|} 
EURO STOXX \\
$\mathbf{5 0}$ \\
\end{tabular} & 0.4683 & STRAITS TIMES & 0.0027 & KOSPI & 0.0033 \\
\hline 6 & FTSE 100 & 0.4791 & IBEX 35 & 0.4696 & BOVESPA & 0.0035 & \begin{tabular}{|l|} 
OMX \\
STOCKHOLM
\end{tabular} & 0.0144 \\
\hline 7 & KOSPI & 0.4791 & S\&P ASX 200 & 0.4785 & TSE300 & 0.0041 & TSE300 & 0.0075 \\
\hline 8 & UK 100 & 0.4796 & CAC40 & 0.4797 & \begin{tabular}{|l} 
S\&P TSX \\
COMPOSITE
\end{tabular} & 0.0044 & $\begin{array}{l}\text { S\&P TSX } \\
\text { COMPOSITE }\end{array}$ & 0.0076 \\
\hline 9 & PX & 0.4851 & FTSE 100 & 0.4835 & ALL ORDINARIES & 0.0055 & BIST 100 & 0.0092 \\
\hline 10 & CAC40 & 0.4936 & UK 100 & 0.4837 & CAC40 & 0.0064 & UK 100 & 0.0163 \\
\hline 11 & BOVESPA & 0.4965 & \begin{tabular}{|l|} 
OMX \\
STOCKHOLM
\end{tabular} & 0.4856 & SMI & 0.0085 & SET & 0.0096 \\
\hline 12 & MOEX & 0.4975 & OMX S30 & 0.486 & ATX & 0.0093 & XU 100 & 0.0096 \\
\hline 13 & S\&P ASX 200 & 0.4994 & $\mathrm{PX}$ & 0.4862 & \begin{tabular}{|l|} 
OMX \\
STOCKHOLM
\end{tabular} & 0.0123 & $\begin{array}{l}\text { STRAITS } \\
\text { TIMES } \\
\end{array}$ & 0.0096 \\
\hline 14 & BIST 100 & 0.5018 & \begin{tabular}{|l|} 
ALL \\
ORDINARIES \\
\end{tabular} & 0.4924 & OMX S30 & 0.0125 & DAX & 0.0101 \\
\hline 15 & XU 100 & 0.5023 & KLCI & 0.4925 & HANG SENG & 0.0131 & BEL20 & 0.0102 \\
\hline 16 & $\begin{array}{l}\text { STRAITS } \\
\text { TIMES }\end{array}$ & 0.5027 & KOSPI & 0.5033 & TAIEX & 0.014 & AEX & 0.0117 \\
\hline 17 & TSE300 & 0.5041 & TSE300 & 0.5075 & PX & 0.0149 & FTSE 100 & 0.0165 \\
\hline 18 & \begin{tabular}{|l|} 
S\&P TSX \\
COMPOSITE
\end{tabular} & 0.5044 & \begin{tabular}{|l} 
S\&P TSX \\
COMPOSITE \\
\end{tabular} & 0.5076 & UK 100 & 0.0204 & CAC40 & 0.0203 \\
\hline 19 & \begin{tabular}{|l|} 
ALL \\
ORDINARIES
\end{tabular} & 0.5055 & BIST 100 & 0.5092 & FTSE 100 & 0.0209 & IBEX 35 & 0.0304 \\
\hline 20 & SMI & 0.5085 & SET & 0.5096 & KOSPI & 0.0209 & S\&P ASX 200 & 0.0215 \\
\hline 21 & ATX & 0.5093 & XU 100 & 0.5096 & IBEX 35 & 0.0213 & \begin{tabular}{|l|} 
EURO STOXX \\
$\mathbf{5 0}$
\end{tabular} & 0.0317 \\
\hline 22 & \begin{tabular}{|l|} 
OMX \\
STOCKHOLM
\end{tabular} & 0.5123 & STRAITS TIMES & 0.5096 & AEX & 0.0224 & EOE & 0.0119 \\
\hline 23 & OMX S30 & 0.5125 & DAX & 0.5101 & EOE & 0.0224 & PSEI & 0.0138 \\
\hline 24 & HANG SENG & 0.5131 & BEL20 & 0.5102 & EURO STOXX 50 & 0.0227 & $\begin{array}{l}\text { FTSE } \\
\text { MIBTEL }\end{array}$ & 0.035 \\
\hline 25 & TAIEX & 0.514 & AEX & 0.5117 & WIG & 0.0229 & DJUA & 0.0159 \\
\hline 26 & AEX & 0.5224 & EOE & 0.5119 & KLCI & 0.0239 & RTSI & 0.0207 \\
\hline 27 & EOE & 0.5224 & PSEI & 0.5138 & IPC & 0.0271 & SMI & 0.036 \\
\hline 28 & WIG & 0.5229 & DJUA & 0.5159 & FTSE MIBTEL & 0.0273 & IPC & 0.0388 \\
\hline 29 & KLCI & 0.5239 & RTSI & 0.5207 & MEXICIPC & 0.0273 & MEXICIPC & 0.0391 \\
\hline 30 & HEX & 0.5276 & HANG SENG & 0.5236 & HEX & 0.0276 & HANG SENG & 0.0236 \\
\hline 31 & DJUA & 0.5283 & BOVESPA & 0.5249 & DJUA & 0.0283 & BOVESPA & \begin{tabular}{|l|}
0.0249 \\
\end{tabular} \\
\hline 32 & BEL20 & 0.5285 & HEX & 0.5254 & BEL20 & 0.0285 & HEX & 0.0254 \\
\hline 33 & RTSI & 0.5296 & TAIEX & 0.5271 & RTSI & 0.0296 & TAIEX & \begin{tabular}{|l|}
0.0271 \\
\end{tabular} \\
\hline
\end{tabular}




\begin{tabular}{|c|c|c|c|c|c|c|c|c|}
\hline 34 & DAX & 0.5302 & ATX & 0.5283 & DAX & 0.0302 & ATX & 0.0283 \\
\hline 35 & SET & 0.5326 & TA 35 & 0.5288 & SET & 0.0326 & TA 35 & 0.0288 \\
\hline 36 & IPSA & 0.5331 & MOEX & 0.5321 & IPSA & 0.0331 & MOEX & 0.0321 \\
\hline 37 & $\begin{array}{l}\text { IDX } \\
\text { COMPOSITE }\end{array}$ & 0.5363 & WIG & 0.5329 & IDX COMPOSITE & 0.0363 & WIG & 0.0329 \\
\hline 38 & $\mathrm{JCI}$ & 0.5366 & JCI & 0.5338 & JCI & 0.0366 & JCI & 0.0338 \\
\hline 39 & TA 35 & 0.5369 & IDX COMPOSITE & 0.534 & TA 35 & 0.0369 & \begin{tabular}{|l} 
IDX \\
COMPOSITE \\
\end{tabular} & 0.034 \\
\hline 40 & China A50 & 0.5407 & DJTA & 0.5352 & China A50 & 0.0407 & DJTA & 0.0352 \\
\hline 41 & $\begin{array}{l}\text { ATHEX } \\
\text { COMPOSITE }\end{array}$ & 0.5433 & NIKKEI & 0.5379 & ATHEX COMPOSITE & 0.0433 & NIKKEI & 0.0379 \\
\hline 42 & RUSSEL & 0.5452 & China A50 & 0.5384 & RUSSEL & 0.0452 & China A50 & 0.0384 \\
\hline 43 & DJTA & 0.5484 & TOPIX & 0.5401 & DJTA & 0.0484 & TOPIX & 0.0401 \\
\hline 44 & BUX & 0.5502 & $\begin{array}{l}\text { ATHEX } \\
\text { COMPOSITE } \\
\end{array}$ & 0.5428 & BUX & 0.0502 & \begin{tabular}{|l} 
ATHEX \\
COMPOSITE
\end{tabular} & 0.0428 \\
\hline 45 & PSEI & 0.5521 & FTSE250 & 0.5446 & PSEI & 0.0521 & FTSE250 & 0.0446 \\
\hline 46 & BET & 0.5526 & RUSSEL & 0.5449 & BET & 0.0526 & RUSSEL & 0.0449 \\
\hline 47 & NIKKEI & 0.5533 & BET & 0.5514 & NIKKEI & 0.0533 & BET & 0.0514 \\
\hline 48 & TOPIX & 0.554 & UX & 0.5551 & TOPIX & 0.054 & UX & 0.0551 \\
\hline 49 & AMEX & 0.5556 & IPSA & 0.5605 & AMEX & 0.0556 & IPSA & 0.0605 \\
\hline 50 & OSE ALL & 0.5557 & OSE ALL & 0.565 & OSE ALL & 0.0557 & OSE ALL & 0.065 \\
\hline 51 & PSI 20 & 0.5557 & PSI 20 & 0.565 & PSI 20 & 0.0557 & PSI 20 & 0.065 \\
\hline 52 & FTSE250 & 0.5581 & MDAX & 0.5669 & FTSE250 & 0.0581 & MDAX & 0.0669 \\
\hline 53 & BSE SENSEX & 0.559 & BSE SENSEX & 0.5678 & BSE SENSEX & 0.059 & BSE SENSEX & 0.0678 \\
\hline 54 & NIFTY 50 & 0.5595 & AMEX & 0.5679 & NIFTY 50 & 0.0595 & AMEX & 0.0679 \\
\hline 55 & UX & 0.5644 & NIFTY 50 & 0.5702 & UX & 0.0644 & NIFTY 50 & 0.0702 \\
\hline 56 & DJIA & 0.5689 & SP500 & 0.5743 & DJIA & 0.0689 & SP500 & 0.0743 \\
\hline 57 & BSHARES & 0.5713 & \begin{tabular}{|l} 
Shanghai \\
Composite
\end{tabular} & 0.5789 & BSHARES & 0.0713 & $\begin{array}{l}\text { Shanghai } \\
\text { Composite }\end{array}$ & 0.0789 \\
\hline 58 & \begin{tabular}{|l} 
Shanghai \\
Composite
\end{tabular} & 0.5715 & DJIA & 0.5811 & Shanghai Composite & 0.0715 & DJIA & 0.0811 \\
\hline 59 & SP500 & 0.5744 & $\begin{array}{l}\text { CSE ALL } \\
\text { SHARES }\end{array}$ & 0.5816 & SP500 & 0.0744 & $\begin{array}{l}\text { CSE ALL } \\
\text { SHARES }\end{array}$ & 0.0816 \\
\hline 60 & OMX TALLINN & 0.5772 & BSHARES & 0.583 & OMX TALLINN & 0.0772 & BSHARES & 0.083 \\
\hline 61 & MDAX & 0.5779 & SOFIX & 0.591 & MDAX & 0.0779 & SOFIX & 0.091 \\
\hline 62 & SAX & 0.5841 & NASDAQ & 0.5918 & SAX & 0.0841 & NASDAQ & 0.0918 \\
\hline 63 & $\begin{array}{l}\text { CSE ALL } \\
\text { SHARES }\end{array}$ & 0.5863 & SAX & 0.5944 & CSE ALL SHARES & 0.0863 & SAX & 0.0944 \\
\hline 64 & NASDAQ & 0.5866 & NASDAQ 100 & 0.5976 & NASDAQ & 0.0866 & NASDAQ 100 & 0.0976 \\
\hline 65 & OMX RIGA & 0.5888 & OMX TALLINN & 0.5992 & OMX RIGA & 0.0888 & \begin{tabular}{|l} 
OMX \\
TALLINN
\end{tabular} & 0.0992 \\
\hline 66 & NASDAQ 100 & 0.5918 & BUX & 0.5996 & NASDAQ 100 & 0.0918 & BUX & 0.0996 \\
\hline 67 & SOFIX & 0.5935 & TECDAX & 0.602 & SOFIX & 0.0935 & TECDAX & 0.102 \\
\hline 68 & TECDAX & 0.5971 & SDAX & 0.6033 & TECDAX & 0.0971 & SDAX & 0.1033 \\
\hline 69 & SDAX & 0.6034 & BUENOS & 0.6266 & SDAX & 0.1034 & BUENOS & 0.1266 \\
\hline 70 & OMX VILNIUS & 0.6214 & MERVAL & 0.6267 & OMX VILNIUS & 0.1214 & MERVAL & 0.1267 \\
\hline 71 & BUENOS & 0.6276 & OMX VILNIUS & 0.6371 & BUENOS & 0.1276 & OMX VILNIUS & 0.1371 \\
\hline 72 & MERVAL & 0.6278 & OMX RIGA & 0.645 & MERVAL & 0.1278 & OMX RIGA & 0.145 \\
\hline 73 & SASESLCT & 0.6409 & SASESLCT & 0.6516 & SASESLCT & 0.1409 & SASESLCT & 0.1516 \\
\hline 74 & NZ 50 & 0.6596 & NZ 50 & 0.6594 & NZ 50 & 0.1596 & NZ 50 & 0.1594 \\
\hline
\end{tabular}

Source: own calculations. 


\section{Appendix 3}

First and the second ranking of currency pairs

Cases when both currencies are form developed countries are marked in bold

\begin{tabular}{|c|c|c|c|c|c|c|c|c|}
\hline & \multicolumn{4}{|c|}{ First ranking } & \multicolumn{4}{|c|}{ Second ranking } \\
\hline Ranking & Currency pair & $H_{1250}$ & Currency pair & $H_{625}$ & Currency pair & $\left|H_{1250}-0.5\right|$ & Currency pair & $\left|H_{625}-0.5\right|$ \\
\hline 1 & AUDCAD & 0.4159 & EURDKK & 0.3665 & EURXPD & 0.0003 & USDPLN & 0.0005 \\
\hline 2 & EURDKK & 0.4168 & AUDCAD & 0.4022 & USDXAG & 0.0005 & GBPCAD & 0.0010 \\
\hline 3 & EURRON & 0.4258 & EURRON & 0.4062 & JPYZAR & 0.0009 & JPYSEK & 0.0013 \\
\hline 4 & EURPLN & 0.4395 & JPYXAG & 0.4243 & JPYAUD & 0.0014 & JPYTHB & 0.0013 \\
\hline 5 & EURHUF & 0.4415 & JPYXAU & 0.4298 & JPYSEK & 0.0015 & EURILS & 0.0020 \\
\hline 6 & JPYXAU & 0.4495 & EURHUF & 0.4332 & EURILS & 0.0016 & JPYCLP & 0.0025 \\
\hline 7 & JPYXAG & 0.4580 & EURPLN & 0.4370 & AUDNZD & 0.0016 & EURTHB & 0.0035 \\
\hline 8 & AUDPLN & 0.4654 & AUDPLN & 0.4458 & JPYNAD & 0.0024 & USDEURO & 0.0035 \\
\hline 9 & EURCAD & 0.4699 & EURAUD & 0.4544 & EURGBP & 0.0027 & JPYSGD & 0.0043 \\
\hline 10 & EURSEK & 0.4758 & AUDNZD & 0.4566 & USDILS & 0.0030 & USDSDG & 0.0044 \\
\hline 11 & EURSDG & 0.4762 & EURXAG & 0.4567 & USDPHP & 0.0030 & JPYZAR & 0.0053 \\
\hline 12 & EURAUD & 0.4769 & EURCAD & 0.4568 & USDSDG & 0.0030 & USDCZK & 0.0053 \\
\hline 13 & GBPPLN & 0.4775 & USDXAG & 0.4621 & EURNOK & 0.0031 & EURJPY & 0.0054 \\
\hline 14 & USDHKD & 0.4775 & USDXAU & 0.4665 & EURTHB & 0.0031 & JPYNOK & 0.0055 \\
\hline 15 & JPYXPT & 0.4802 & EURSDG & 0.4704 & USDXAU & 0.0043 & EURXPD & 0.0063 \\
\hline 16 & EURCZK & 0.4809 & NZDJPY & 0.4731 & USDPLN & 0.0046 & USDKRW & 0.0063 \\
\hline 17 & EURXPT & 0.4839 & JPYNZD & 0.4745 & GBPCAD & 0.0047 & USDNZD & 0.0067 \\
\hline 18 & EURNZD & 0.4866 & EURXPT & 0.4774 & JPYCZK & 0.0050 & USDAUD & 0.0075 \\
\hline 19 & USDNZD & 0.4875 & EURNAD & 0.4777 & USDKRW & 0.0051 & JPYHKD & 0.0081 \\
\hline 20 & EURXAG & 0.4890 & EURCZK & 0.4779 & NZDJPY & 0.0051 & EURCLP & 0.0086 \\
\hline 21 & USDHUF & 0.4904 & EURXAU & 0.4796 & JPYHUF & 0.0055 & JPYHUF & 0.0088 \\
\hline 22 & JPYNOK & 0.4911 & GBPPLN & 0.4808 & EURXAU & 0.0063 & USDJPY & 0.0089 \\
\hline 23 & EURMXN & 0.4932 & JPYXPT & 0.4816 & USDEURO & 0.0065 & JPYPLN & 0.0090 \\
\hline 24 & EURXAU & 0.4937 & EURZAR & 0.4845 & EURMXN & 0.0068 & JPYCZK & 0.0093 \\
\hline 25 & NZDJPY & 0.4949 & USDHKD & 0.4846 & USDXDR & 0.0071 & JPYAUD & 0.0094 \\
\hline 26 & USDKRW & 0.4949 & EURNOK & 0.4858 & JPYNZD & 0.0082 & JPYCAD & 0.0096 \\
\hline 27 & USDPLN & 0.4954 & EURSEK & 0.4867 & USDGBP & 0.0087 & JPYILS & 0.0096 \\
\hline 28 & USDXAU & 0.4957 & USDHUF & 0.4870 & JPYNOK & 0.0089 & EURMXN & 0.0098 \\
\hline 29 & EURTHB & 0.4969 & EURNZD & 0.4888 & USDHUF & 0.0096 & USDILS & 0.0103 \\
\hline 30 & USDSDG & 0.4970 & JPYNAD & 0.4888 & EURXAG & 0.0110 & USDPHP & 0.0103 \\
\hline 31 & USDILS & 0.4970 & USDILS & 0.4897 & EURCLP & 0.0113 & USDXDR & 0.0106 \\
\hline 32 & USDPHP & 0.4970 & USDPHP & 0.4897 & USDSEK & 0.0114 & EURGBP & 0.0108 \\
\hline 33 & JPYNAD & 0.4976 & JPYAUD & 0.4906 & JPYPLN & 0.0121 & JPYNAD & 0.0112 \\
\hline 34 & EURILS & 0.4984 & JPYCZK & 0.4907 & USDNZD & 0.0125 & EURNZD & 0.0112 \\
\hline 35 & JPYAUD & 0.4986 & USDJPY & 0.4911 & EURNZD & 0.0134 & USDXPT & 0.0119 \\
\hline 36 & JPYZAR & 0.4991 & JPYHUF & 0.4912 & EURZAR & 0.0145 & EURHKD & 0.0120 \\
\hline 37 & EURXPD & 0.4997 & EURCLP & 0.4914 & USDCZK & 0.0147 & JPYXPD & 0.0127 \\
\hline 38 & USDXAG & 0.5005 & USDNZD & 0.4933 & JPYCAD & 0.0148 & USDHUF & 0.0130 \\
\hline 39 & JPYSEK & 0.5015 & USDKRW & 0.4937 & EURXPT & 0.0161 & EURSEK & 0.0133 \\
\hline 40 & AUDNZD & 0.5016 & JPYZAR & 0.4947 & USDXPD & 0.0166 & EURNOK & 0.0142 \\
\hline 41 & EURGBP & 0.5027 & USDSDG & 0.4956 & EURJPY & 0.0168 & GBPCHF & 0.0148 \\
\hline 42 & EURNOK & 0.5031 & JPYSGD & 0.4957 & USDAUD & 0.0169 & USDHKD & 0.0154 \\
\hline 43 & GBPCAD & 0.5047 & EURTHB & 0.4965 & GBPCHF & 0.0177 & EURZAR & 0.0155 \\
\hline
\end{tabular}




\begin{tabular}{|c|c|c|c|c|c|c|c|c|}
\hline 44 & JPYCZK & 0.5050 & JPYSEK & 0.4987 & EURCZK & 0.0191 & EURKRW & 0.0166 \\
\hline 45 & JPYHUF & 0.5055 & GBPCAD & 0.4990 & JPYXPD & 0.0197 & GBPAUD & 0.0173 \\
\hline 46 & USDEURO & 0.5065 & USDPLN & 0.5005 & JPYXPT & 0.0198 & USDNOK & 0.0176 \\
\hline 47 & USDXDR & 0.5071 & JPYTHB & 0.5013 & USDCHF & 0.0198 & USDDKK & 0.0178 \\
\hline 48 & JPYNZD & 0.5082 & EURILS & 0.5020 & EURNAD & 0.0209 & USDSEK & 0.0182 \\
\hline 49 & USDGBP & 0.5087 & JPYCLP & 0.5025 & JPYTHB & 0.0215 & JPYXPT & 0.0184 \\
\hline 50 & EURCLP & 0.5113 & USDEURO & 0.5035 & USDTHB & 0.0216 & GBPPLN & 0.0192 \\
\hline 51 & USDSEK & 0.5114 & USDCZK & 0.5053 & EURHKD & 0.0220 & EURMYR & 0.0195 \\
\hline 52 & JPYPLN & 0.5121 & EURJPY & 0.5054 & GBPNZD & 0.0221 & EURXAU & 0.0204 \\
\hline 53 & EURZAR & 0.5145 & JPYNOK & 0.5055 & GBPAUD & 0.0222 & JPYINR & 0.0217 \\
\hline 54 & USDCZK & 0.5147 & EURXPD & 0.5063 & USDHKD & 0.0225 & USDNAD & 0.0219 \\
\hline 55 & JPYCAD & 0.5148 & USDAUD & 0.5075 & GBPPLN & 0.0225 & EURCZK & 0.0221 \\
\hline 56 & USDXPD & 0.5166 & JPYHKD & 0.5081 & USDISK & 0.0227 & EURNAD & 0.0223 \\
\hline 57 & EURJPY & 0.5168 & JPYPLN & 0.5090 & JPYCLP & 0.0229 & USDCHF & 0.0224 \\
\hline 58 & USDAUD & 0.5169 & JPYCAD & 0.5096 & EURAUD & 0.0231 & EURXPT & 0.0226 \\
\hline 59 & GBPCHF & 0.5177 & JPYILS & 0.5096 & EURKRW & 0.0232 & JPYRON & 0.0231 \\
\hline 60 & JPYXPD & 0.5197 & EURMXN & 0.5098 & EURSDG & 0.0238 & USDZAR & 0.0232 \\
\hline 61 & USDCHF & 0.5198 & USDXDR & 0.5106 & EURSEK & 0.0242 & USDRON & 0.0247 \\
\hline 62 & EURNAD & 0.5209 & EURGBP & 0.5108 & EURMYR & 0.0249 & JPYNZD & 0.0255 \\
\hline 63 & JPYTHB & 0.5215 & USDXPT & 0.5119 & USDJPY & 0.0255 & NZDJPY & 0.0269 \\
\hline 64 & USDTHB & 0.5216 & EURHKD & 0.5120 & USDXPT & 0.0256 & USDXPD & 0.0277 \\
\hline 65 & EURHKD & 0.5220 & JPYXPD & 0.5127 & USDNOK & 0.0261 & AUDCHF & 0.0293 \\
\hline 66 & GBPNZD & 0.5221 & GBPCHF & 0.5148 & USDRON & 0.0277 & EURSDG & 0.0296 \\
\hline 67 & GBPAUD & 0.5222 & EURKRW & 0.5166 & EURCAD & 0.0301 & GBPNZD & 0.0297 \\
\hline 68 & USDISK & 0.5227 & GBPAUD & 0.5173 & JPYINR & 0.0326 & JPYDKK & 0.0298 \\
\hline 69 & JPYCLP & 0.5229 & USDNOK & 0.5176 & USDCNY & 0.0337 & USDTHB & 0.0309 \\
\hline 70 & EURKRW & 0.5232 & USDDKK & 0.5178 & AUDCHF & 0.0344 & CADCHF & 0.0310 \\
\hline 71 & EURMYR & 0.5249 & USDSEK & 0.5182 & AUDPLN & 0.0346 & JPYBRL & 0.0313 \\
\hline 72 & USDJPY & 0.5255 & EURMYR & 0.5195 & JPYBRL & 0.0352 & JPYMXN & 0.0327 \\
\hline 73 & USDXPT & 0.5256 & JPYINR & 0.5217 & JPYSGD & 0.0361 & USDXAU & 0.0335 \\
\hline 74 & USDNOK & 0.5261 & USDNAD & 0.5219 & JPYMXN & 0.0380 & USDISK & 0.0346 \\
\hline 75 & USDRON & 0.5277 & USDCHF & 0.5224 & CADCHF & 0.0391 & JPYGBP & 0.0352 \\
\hline 76 & JPYINR & 0.5326 & JPYRON & 0.5231 & JPYGBP & 0.0406 & USDGBP & 0.0366 \\
\hline 77 & USDCNY & 0.5337 & USDZAR & 0.5232 & JPYXAG & 0.0420 & JPYMYR & 0.0374 \\
\hline 78 & AUDCHF & 0.5344 & USDRON & 0.5247 & JPYIDR & 0.0428 & JPYKRW & 0.0376 \\
\hline 79 & JPYBRL & 0.5352 & USDXPD & 0.5277 & EURTWD & 0.0446 & USDXAG & 0.0379 \\
\hline 80 & JPYSGD & 0.5361 & AUDCHF & 0.5293 & USDDKK & 0.0453 & USDMXN & 0.0393 \\
\hline 81 & JPYMXN & 0.5380 & GBPNZD & 0.5297 & USDCAD & 0.0455 & JPYISK & 0.0396 \\
\hline 82 & CADCHF & 0.5391 & JPYDKK & 0.5298 & JPYMYR & 0.0460 & EURINR & 0.0411 \\
\hline 83 & JPYGBP & 0.5406 & USDTHB & 0.5309 & USDZAR & 0.0478 & EURCNY & 0.0414 \\
\hline 84 & JPYIDR & 0.5428 & CADCHF & 0.5310 & JPYRON & 0.0485 & USDCAD & 0.0421 \\
\hline 85 & EURTWD & 0.5446 & JPYBRL & 0.5313 & JPYXAU & 0.0505 & EURCAD & 0.0432 \\
\hline 86 & USDDKK & 0.5453 & JPYMXN & 0.5327 & JPYILS & 0.0516 & EURXAG & 0.0433 \\
\hline 87 & USDCAD & 0.5455 & USDISK & 0.5346 & EURCNY & 0.0519 & AUDNZD & 0.0434 \\
\hline 88 & JPYMYR & 0.5460 & JPYGBP & 0.5352 & JPYHKD & 0.0522 & EURTWD & 0.0440 \\
\hline 89 & USDZAR & 0.5478 & USDGBP & 0.5366 & USDMXN & 0.0547 & EURBRL & 0.0449 \\
\hline 90 & JPYRON & 0.5485 & JPYMYR & 0.5374 & JPYTRY & 0.0578 & EURAUD & 0.0456 \\
\hline 91 & JPYILS & 0.5516 & JPYKRW & 0.5376 & USDNAD & 0.0579 & JPYTWD & 0.0483 \\
\hline 92 & EURCNY & 0.5519 & USDMXN & 0.5393 & EURHUF & 0.0585 & USDTWD & 0.0493 \\
\hline 93 & JPYHKD & 0.5522 & JPYISK & 0.5396 & EURBRL & 0.0587 & JPYPHP & 0.0520 \\
\hline
\end{tabular}




\begin{tabular}{|c|c|c|c|c|c|c|c|c|}
\hline 94 & USDMXN & 0.5547 & EURINR & 0.5411 & EURINR & 0.0599 & AUDPLN & 0.0542 \\
\hline 95 & JPYTRY & 0.5578 & EURCNY & 0.5414 & EURPLN & 0.0605 & JPYRUB & 0.0559 \\
\hline 96 & USDNAD & 0.5579 & USDCAD & 0.5421 & JPYISK & 0.0612 & JPYIDR & 0.0569 \\
\hline 97 & EURBRL & 0.5587 & EURTWD & 0.5440 & EURPHP & 0.0614 & JPYCNY & 0.0577 \\
\hline 98 & EURINR & 0.5599 & EURBRL & 0.5449 & USDTWD & 0.0644 & USDCLP & 0.0579 \\
\hline 99 & JPYISK & 0.5612 & JPYTWD & 0.5483 & JPYDKK & 0.0654 & EURPHP & 0.0589 \\
\hline 100 & EURPHP & 0.5614 & USDTWD & 0.5493 & JPYCHF & 0.0712 & EURPLN & 0.0630 \\
\hline 101 & USDTWD & 0.5644 & JPYPHP & 0.5520 & JPYKRW & 0.0713 & JPYCHF & 0.0634 \\
\hline 102 & JPYDKK & 0.5654 & JPYRUB & 0.5559 & JPYCNY & 0.0730 & EURHUF & 0.0668 \\
\hline 103 & JPYCHF & 0.5712 & JPYIDR & 0.5569 & JPYRUB & 0.0733 & EURHRK & 0.0672 \\
\hline 104 & JPYKRW & 0.5713 & JPYCNY & 0.5577 & JPYPHP & 0.0742 & JPYXDR & 0.0689 \\
\hline 105 & JPYCNY & 0.5730 & USDCLP & 0.5579 & EURRON & 0.0742 & USDINR & 0.0690 \\
\hline 106 & JPYRUB & 0.5733 & EURPHP & 0.5589 & CHFPLN & 0.0746 & JPYXAU & 0.0702 \\
\hline 107 & JPYPHP & 0.5742 & JPYCHF & 0.5634 & USDCLP & 0.0756 & USDCNY & 0.0720 \\
\hline 108 & CHFPLN & 0.5746 & EURHRK & 0.5672 & JPYTWD & 0.0790 & EURRUB & 0.0731 \\
\hline 109 & USDCLP & 0.5756 & JPYXDR & 0.5689 & EURHRK & 0.0790 & CHFPLN & 0.0744 \\
\hline 110 & JPYTWD & 0.5790 & USDINR & 0.5690 & EURTRY & 0.0791 & JPYXAG & 0.0757 \\
\hline 111 & EURHRK & 0.5790 & USDCNY & 0.5720 & EURXDR & 0.0826 & USDBRL & 0.0761 \\
\hline 112 & EURTRY & 0.5791 & EURRUB & 0.5731 & JPYXDR & 0.0829 & EURXDR & 0.0865 \\
\hline 113 & EURXDR & 0.5826 & CHFPLN & 0.5744 & EURDKK & 0.0832 & EURIDR & 0.0868 \\
\hline 114 & JPYXDR & 0.5829 & USDBRL & 0.5761 & EURISK & 0.0834 & JPYHRK & 0.0899 \\
\hline 115 & EURISK & 0.5834 & EURXDR & 0.5865 & AUDCAD & 0.0841 & USDRUB & 0.0924 \\
\hline 116 & USDINR & 0.5867 & EURIDR & 0.5868 & USDINR & 0.0867 & EURRON & 0.0938 \\
\hline 117 & USDMYR & 0.5924 & JPYHRK & 0.5899 & USDMYR & 0.0924 & JPYTRY & 0.0945 \\
\hline 118 & USDBRL & 0.5951 & USDRUB & 0.5924 & USDBRL & 0.0951 & AUDCAD & 0.0978 \\
\hline 119 & EURRUB & 0.6002 & JPYTRY & 0.5945 & EURRUB & 0.1002 & USDMYR & 0.0983 \\
\hline 120 & EURIDR & 0.6023 & USDMYR & 0.5983 & EURIDR & 0.1023 & USDHRK & 0.0988 \\
\hline 121 & JPYHRK & 0.6025 & USDHRK & 0.5988 & JPYHRK & 0.1025 & EURISK & 0.0995 \\
\hline 122 & USDBGN & 0.6041 & EURISK & 0.5995 & USDBGN & 0.1041 & JPYBGN & 0.1020 \\
\hline 123 & USDHRK & 0.6042 & JPYBGN & 0.6020 & USDHRK & 0.1042 & EURTRY & 0.1045 \\
\hline 124 & EURCHF & 0.6075 & EURTRY & 0.6045 & EURCHF & 0.1075 & EURCHF & 0.1049 \\
\hline 125 & JPYBGN & 0.6125 & EURCHF & 0.6049 & JPYBGN & 0.1125 & USDBGN & 0.1059 \\
\hline 126 & USDTRY & 0.6138 & USDBGN & 0.6059 & USDTRY & 0.1138 & USDTRY & 0.1305 \\
\hline 127 & USDRUB & 0.6160 & USDTRY & 0.6305 & USDRUB & 0.1160 & EURDKK & 0.1335 \\
\hline 128 & JPYEGP & 0.6254 & USDIDR & 0.6345 & JPYEGP & 0.1254 & USDIDR & 0.1345 \\
\hline 129 & EUREGP & 0.6271 & JPYUAH & 0.6640 & EUREGP & 0.1271 & JPYUAH & 0.1640 \\
\hline 130 & USDIDR & 0.6385 & JPYEGP & 0.6656 & USDIDR & 0.1385 & JPYEGP & 0.1656 \\
\hline 131 & JPYUAH & 0.6805 & EUREGP & 0.6673 & JPYUAH & 0.1805 & EUREGP & 0.1673 \\
\hline 132 & EURUAH & 0.6961 & EURUAH & 0.6758 & EURUAH & 0.1961 & EURUAH & 0.1758 \\
\hline 133 & USDUAH & 0.7368 & USDUAH & 0.7161 & USDUAH & 0.2368 & USDUAH & 0.2161 \\
\hline 134 & USDEGP & 0.7518 & USDEGP & 0.7366 & USDEGP & 0.2518 & USDEGP & 0.2366 \\
\hline 135 & EURBGN & 0.7649 & EURBGN & 0.7743 & EURBGN & 0.2649 & EURBGN & 0.2743 \\
\hline
\end{tabular}

Source: own calculations. 